\title{
The Effects of Remote Internal Tides on Continental Slope Internal Tide Generation
}

\author{
Yankun Gong, Matthew D. Rayson, Nicole L. Jones, and Gregory N. IVey \\ Oceans Graduate School and Oceans Institute, University of Western Australia, Perth, Western Australia, Australia
}

(Manuscript received 24 August 2018, in final form 31 March 2019)

\begin{abstract}
Internal tide generation at sloping topography is nominally determined by the local slope geometry, density stratification, and tidal forcing. Recent global ocean models have revealed that remotely generated internal tides (RITs) can also influence locally generated internal tides (LITs). Field measurements with through-the-water column moorings on the southern portion of the Australian North West Shelf (NWS) suggested that RITs led to local regions with either positive or negative barotropic to baroclinic energy conversion. Three-dimensional numerical simulations were used to examine the role of RITs on local internal tide climatology on the inner slope and shelf portion of the NWS. The model demonstrated the principle remote generation site was the western portion of the offshore Exmouth Plateau. Extending the model domain to include this offshore plateau region increased the local net energy conversion on the inner shelf by $13.5 \%$ and on the slope by $8 \%$. Simulations using an idealized 2D model configuration aligned along the principal direction of RIT propagation demonstrated that the sign and magnitude of the local energy conversion was dependent on the distance between the remote and local generation sites, the phase difference between the local barotropic tide and the RIT, and the amplitude of both the local barotropic tide and the RIT. For RITs with a low-wave Froude number $(\mathrm{Fr}<0.05)$, where Fr is the ratio of the internal wave baroclinic velocity to the linear wave speed, the conversion rates were consistent with kinematic predictions based on the phase difference only. For stronger flows with $\mathrm{Fr}>0.05$, the conversion rates showed a nonlinear dependence on Fr.
\end{abstract}

\section{Introduction}

The interaction of the oscillatory surface (i.e., barotropic) tide with sloping topography in the densitystratified interior of the ocean produces internal (i.e., baroclinic) tides (e.g., Garrett and Kunze 2007). The resulting baroclinic perturbations can then propagate for large distances (over $1000 \mathrm{~km}$ ) from the generation site (Zhao and Alford 2009) with typically minimal energy loss (Alford et al. 2007; Kerry et al. 2013). Remotely generated internal tides (hereinafter RITs) from multiple far-field locations can thus interact with locally generated internal tides (hereinafter LITs), resulting in a complicated internal tide climatology. Here we explore the interaction between RITs and LITs.

The barotropic-to-baroclinic energy conversion rate $C$ and the baroclinic energy flux $\mathbf{F}_{\mathrm{bc}}$ quantify the

Corresponding author: Yankun Gong, yankun.gong@research. uwa.edu.au generation and propagation characteristics of internal tides, respectively. The conversion rate is given by $C=$ $\left.\left(p^{\prime} w_{\mathrm{bt}}\right)\right|_{z=-H}$ (Kurapov et al. 2003; Kelly and Nash 2010). Here, $p^{\prime}$ and $w_{\mathrm{bt}}$ represent the baroclinic pressure perturbation and the vertical component of the barotropic velocity, respectively. The depth-integrated baroclinic energy flux is defined as $\mathbf{F}_{b c}=\int_{-H}^{0}\left(p^{\prime} \mathbf{u}_{b c}\right) d z$, in which $\mathbf{u}_{b c}$ represents the horizontal baroclinic velocity (note that bold variables indicate a vector quantity throughout the paper).

Positive conversion rates are common in regional numerical models, representing conversion from barotropic to baroclinic tides. As well as regions of positive conversion rate, regions with negative values of conversion rate have been found in many regional models (e.g., Nagai and Hibiya 2015; Kerry et al. 2013; Ponte and Cornuelle 2013; Zilberman et al. 2009). Negative conversion rates occur when the phase difference between the local pressure perturbation and the barotropic vertical velocity is larger than $90^{\circ}$ on the bottom, and this occurs when RITs make a significant contribution to the 
local conditions (Kelly and Nash 2010). While negative conversion rates arise in numerical models, they have rarely been observed in field measurements. In the present work, we examine the occurrence of negative conversion rates via both observational data, at mooring stations on the southern portion of the Australian North West Shelf (NWS), as well as with numerical modeling.

The influence of RIT signals is often seen in continental shelf observations (Lerczak et al. 2003; Nash et al. 2004), producing changes in the local internal tide field (Kelly and Nash 2010). To investigate the effect of RITs, Kerry et al. (2013) compared results from three numerical simulations, each with different domain sizes, and concluded that in the absence of RITs, domainintegrated conversion rates were $11 \%$ greater at the Luzon Strait and $65 \%$ greater at the Mariana Arc. Based on a two-dimensional (2D) Massachusetts Institute of Technology General Circulation Model (MITgcm), Buijsman et al. (2012) and Klymak et al. (2013) both demonstrated the conversion rates varied with the distance between two adjacent knife ridges. However, the contribution of both the remote and local tidal characteristics, and the distance between generation sites, on local conversion rates over the slope and shelf has not yet been quantitatively examined. In energetic shelf locations (e.g., the NWS), this process can become further complicated by the evolution of largeamplitude linear RITs into nonlinear internal waves (NLIWs) as they move onto the shelf (Holloway et al. 1997), significantly influencing the local internal tide climatology.

There are two main goals in this paper: 1) quantifying the baroclinic energy distribution and examining the spatial distribution of negative conversion rates on the southern NWS and 2) examining the effects of varying phase and amplitude of the RITs on the local internal tide climatology. The structure of this paper is as follows: in section 2 the relevant theoretical framework of internal tides is introduced in detail; in section 3 we present our study site, field mooring stations, model configurations, and data analysis methodology; and in section 4 we describe the internal tidal energetics, the phase difference mechanism leading to negative conversion rates, and the linear effects of the RITs. In section 5 we discuss the effects of nonlinearity on the RITs and the steepening processes. Finally, in section 6 we summarize the key results from this work.

\section{Theoretical framework}

The hydrostatic perturbation pressure $p^{\prime}$ associated with an internal tide-induced vertical isopycnal displacement $\eta$ can be calculated for a particular stratification profile $N(z)$ from

$$
0=\frac{1}{\rho_{0}} \frac{\partial p^{\prime}}{\partial z}+N^{2} \eta
$$

Integrating Eq. (1) with depth, and satisfying the condition of zero depth-average pressure perturbation, Kunze et al. (2002) showed

$$
\begin{aligned}
p^{\prime}(z)= & \rho_{0}\left[\int_{z}^{0} N^{2}\left(z^{\prime}\right) \eta\left(z^{\prime}\right) d z^{\prime}\right. \\
& \left.-\frac{1}{H} \int_{-H}^{0} \int_{z}^{0} N^{2}\left(z^{\prime}\right) \eta\left(z^{\prime}\right) d z^{\prime} d z\right] .
\end{aligned}
$$

As $p^{\prime}$ has both local $\left(p_{l}^{\prime}\right)$ and remote contributions $\left(p_{r}^{\prime}\right)$, the total conversion rate $C$ can be decomposed into a local conversion rate $C_{l}$ and a remotely influenced conversion rate $C_{r}$. As the phase difference between $p_{l}^{\prime}$ and $w_{\mathrm{bt}}$ is close to zero, $C_{l}$ will always be positive, but $C_{r}$ can be either positive or negative.

To derive an expression for $C_{r}$, we assume a remote generation site and a local generation site separated by a distance $L$, and consider the barotropic tide at a single frequency $\omega$. Since the RIT takes time $T_{p}$ to arrive at the local generation site, the resulting pressure perturbation

$$
\begin{aligned}
p_{r}^{\prime} & =\left.P_{r}^{\prime}\right|_{x=L} \cos \left(\omega t-\theta_{\mathrm{bc}, r}\right), \\
\theta_{\mathrm{bc}, r} & =\left(\theta_{p, r}+\frac{T_{p}}{T_{\mathrm{bt}}} 2 \pi\right) .
\end{aligned}
$$

Here $\theta_{p, r}$ is the phase of RITs at the remote generation site; $T_{\mathrm{bt}}$ is the barotropic tide period and the propagation time is $T_{p}=L / c_{p}$, where $c_{p}$ is the mode- 1 linear phase speed. Parameter $\left.P_{r}^{\prime}\right|_{x=L}$ is the amplitude of the remotely influenced pressure perturbation at the local generation site. The vertical barotropic velocity is $w_{\mathrm{bt}}=$ $\left(\mathbf{U}_{\mathrm{bt}} \cdot \nabla H\right) \cos \left(\omega t-\theta_{\mathrm{bt}, l}\right)$, in which $\mathbf{U}_{\mathrm{bt}}$ is the amplitude of the horizontal barotropic velocity and $\nabla H$ is the topographic slope. Therefore, the tidal cycle-average $C_{r}$ is

$$
C_{r}=\frac{1}{T} \int_{0}^{T}\left(p_{r}^{\prime} w_{\mathrm{bt}}\right) d t=\left.\frac{1}{2} P_{r}^{\prime}\right|_{x=L}\left(\mathbf{U}_{\mathrm{bt}} \cdot \nabla H\right) \cos \left(\theta^{\prime}\right),
$$

in which $\theta=\left(\theta_{\mathrm{bc}, r}-\theta_{\mathrm{bt}, l}\right)$ is the phase contribution of the RIT. The pressure amplitude is related to the horizontal velocity amplitude $P^{\prime}=\rho_{0} c U$, in which $c$ is the group speed for the baroclinic tides (Kelly et al. 2013). In addition, $U$ can be obtained from eigenfunctions $W_{n}(z)$ by solving the Sturm-Liouville equation (e.g., Apel et al. 2007) based on the hydrostatic approximation 


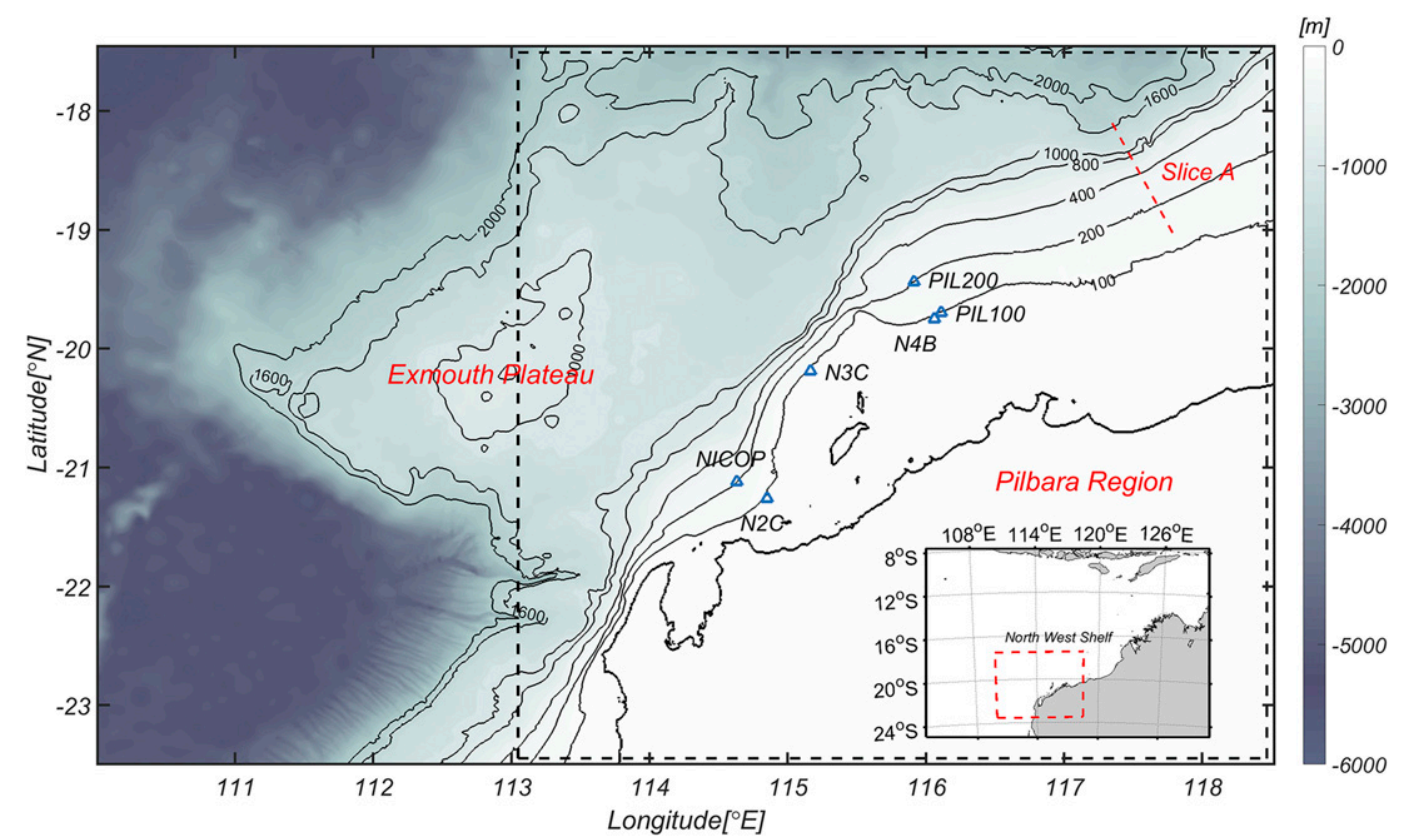

FIG. 1. Bathymetry for the model domain on the NWS (standard case). The black dashed box is the smaller model domain that does not include the western portion of the Exmouth Plateau. Triangles represent the locations of the six moorings used to validate the 3D model and calculate the tidal energy. The red dashed line indicates the slice used to investigate the negative conversion values.

$\frac{d^{2} W_{n}(z)}{d z^{2}}+\frac{N(z)^{2}}{c_{p}^{2}} W_{n}(z)=0, \quad W_{n}(0)=W_{n}(-H)=0$.

The linear phase speed $c_{p}=\omega / k_{h}$, where $k_{h}$ is the horizontal wavenumber. If the buoyancy frequency $N$ is independent of $z$, Eq. (5) then has the normalized analytical solution

$$
W(z)=\sin \left(\frac{N z}{c_{p}}\right) .
$$

Based on the continuity equation, the horizontal baroclinic velocity

$$
u_{\mathrm{bc}}=U \cos \left(\frac{N z}{c_{p}}\right) \sin \left(k_{h} x-\omega t\right),
$$

in which the amplitude of the seabed horizontal velocity $U$ is proportional to $N / \omega$. Thus, the remotely influenced pressure perturbation amplitude at the local generation site is given by

$$
\left.\left.P_{r=L}^{\prime}\right|_{x=\delta} ^{\prime}\right|_{x=R}
$$

where the coefficient $\delta=\left(c_{l} N_{l}\right) /\left(c_{r} N_{r}\right)$. The kinematic prediction of $C_{r}$ in Eq. (4) can thus be rewritten as

$$
C_{r}=\left.\frac{\delta}{2} P_{r}^{\prime}\right|_{x=R}\left(\mathbf{U}_{\mathrm{bt}} \cdot \nabla H\right) \cos \left(\theta^{\prime}\right)
$$

We can see that $C_{r}$ depends on both the amplitudes and phase differences of RITs and the local barotropic tides. We compare the kinematic-predicted $C_{r}$ to numerical model solutions to quantitatively estimate the role of RITs on local energy conversion below.

\section{Methods}

\section{a. Study site}

The study site is located offshore of the Pilbara region on the southern portion of the NWS (Fig. 1). This is a region with a ubiquitous and energetic internal tide, generated by the interaction between the strong semidiurnal surface tides and sloping bottom topography over the continental slope and shelf (Holloway 1984, 1985; Van Gastel et al. 2009; Jones and Ivey 2017). Exmouth Plateau is an elongated plateau in water depths of a $1000 \mathrm{~m}$ or more located offshore of the Pilbara region, which has steep slopes on the western portion (Fig. 1).

Previous studies (Holloway et al. 2001; Van Gastel et al. 2009) modeled the internal wave field of the southern NWS with a limited spatial model domain, excluding the Exmouth Plateau, and concluded that the 
TABLE 1. The position, vertical layout, and sampling regime of the six moorings (PIL200, NICOP, PIL100, N2C, N3C, and N4B) in this study. All ADCPs were upward looking. Note that no thermistors were deployed at the mooring N4B. ASB = above seabed.

\begin{tabular}{|c|c|c|c|c|c|}
\hline $\begin{array}{l}\text { Mooring name and } \\
\text { location }\end{array}$ & $\begin{array}{c}\text { Total } \\
\text { depth }(\mathrm{m})\end{array}$ & $\begin{array}{l}\text { ADCP location } \\
\quad(\mathrm{m} \mathrm{ASB})\end{array}$ & ADCP sampling & $\begin{array}{l}\text { Thermistor location } \\
\text { (m ASB) }\end{array}$ & Thermistor sampling \\
\hline $\begin{array}{l}\text { PIL200 }\left(115.9154^{\circ} \mathrm{E},\right. \\
\left.19.4356^{\circ} \mathrm{S}\right)\end{array}$ & 200 & 8.52 & $\begin{array}{l}\text { 10-m bins, } 10 \text { min } \\
\text { (0008 UTC } 2 \text { Apr to } \\
\text { 0353 UTC } 21 \text { Apr 2012) }\end{array}$ & $\begin{array}{l}5,30,50,80,100,120,140 \\
\quad 160,180\end{array}$ & $\begin{array}{l}1 \mathrm{~min}(0000 \text { UTC } 20 \text { Feb to } \\
1151 \text { UTC } 18 \text { Aug 2012) }\end{array}$ \\
\hline $\begin{array}{l}\text { NICOP } \\
\quad\left(144.6331^{\circ} \mathrm{E},\right. \\
\left.21.1188^{\circ} \mathrm{S}\right)\end{array}$ & 199 & 9.34 & $\begin{array}{l}\text { 5-m bins, } 10 \text { min } \\
\text { (1755 UTC } 8 \text { Nov } 2011 \\
\text { to } 1855 \text { UTC } 20 \text { Apr } \\
\text { 2012) }\end{array}$ & $\begin{array}{l}2.7,21.9,41.9,61.9,80.9 \\
\quad 100,120,140,160,175.5\end{array}$ & $\begin{array}{l}1 \text { min } 40 \text { s }(1000 \text { UTC } 8 \\
\text { Nov } 2011 \text { to } 0019 \text { UTC } \\
13 \text { Apr 2012) }\end{array}$ \\
\hline $\begin{array}{l}\text { PIL100 }\left(116.1116^{\circ} \mathrm{E},\right. \\
\left.19.6944^{\circ} \mathrm{S}\right)\end{array}$ & 100 & 7.52 & $\begin{array}{l}\text { 8-m bins, } 10 \text { min } \\
\quad \text { (1009 UTC } 20 \text { Feb to } \\
\text { 0919 UTC } 18 \text { Aug 2012) }\end{array}$ & $\begin{array}{l}6,10,20,30,40,50,60,70 \\
\quad 80\end{array}$ & $\begin{array}{l}1 \text { min (0800 UTC } 20 \text { Feb to } \\
2203 \text { UTC } 31 \text { May 2012) }\end{array}$ \\
\hline $\begin{array}{l}\mathrm{N} 2 \mathrm{C}\left(114.8406^{\circ} \mathrm{E}\right. \\
\left.\quad 21.2435^{\circ} \mathrm{S}\right)\end{array}$ & 95 & 2.76 & $\begin{array}{l}\text { 2-m bins, } 2.5 \text { min } \\
\text { (0008 UTC } 2 \text { Apr to } \\
\text { 0353 UTC } 21 \text { Apr 2012) }\end{array}$ & $\begin{array}{r}0.5,11.5,21.5,31.5,41.5 \\
\quad 46.5,51.5,61.5,71.5,80.5\end{array}$ & $\begin{array}{l}1 \text { min (1439 UTC } 2 \text { Apr to } \\
0444 \text { UTC } 21 \text { Apr 2012) }\end{array}$ \\
\hline $\begin{array}{l}\mathrm{N} 3 \mathrm{C}\left(115.1645^{\circ} \mathrm{E},\right. \\
\left.20.1866^{\circ} \mathrm{S}\right)\end{array}$ & 91 & 2.76 & $\begin{array}{l}\text { 2-m bins, } 2.5 \mathrm{~min} \\
\quad \text { (1131 UTC } 28 \text { Mar to } \\
\text { 0946 } 4 \text { Apr 2012) }\end{array}$ & $\begin{array}{l}5.5,15.5,20.5,25.5,30.5 \\
\quad 35.5,45.5,55.5,65.5,75.5\end{array}$ & $\begin{array}{l}1 \mathrm{~min}(0729 \text { UTC } 28 \mathrm{Mar} \\
\text { to } 0609 \text { UTC } 14 \mathrm{Apr} \\
\text { 2012) }\end{array}$ \\
\hline $\begin{array}{l}\text { N4B }\left(116.0650^{\circ} \mathrm{E}\right. \\
\left.\quad 19.7448^{\circ} \mathrm{S}\right)\end{array}$ & 87 & 2.76 & $\begin{array}{l}\text { 2-m bins, } 2.5 \mathrm{~min} \\
\quad \text { (0539 UTC } 4 \text { Apr to } \\
\text { 0441 UTC } 22 \text { Apr 2012) }\end{array}$ & - & - \\
\hline
\end{tabular}

continental slope and inshore shelf with water depths of $500 \mathrm{~m}$ or less were the main generation sites. However, the western portion of the Exmouth Plateau also has critical or near critical slope conditions, thereby the region is also likely an important generator of internal tides (as demonstrated in section $4 \mathrm{~b}$ ). The southern NWS is therefore an ideal site to examine the influence of RITs on LITs.

\section{b. Field observations}

Moorings were deployed in the Pilbara region from 2011 to 2012 to quantify the regional internal tide dynamics on the southern NWS. Four of these moorings and additional observational data from the PIL200 and PIL100 moorings of the Integrated Marine Observing System (IMOS) were used to determine the regional internal tide characteristics (see blue triangles in Fig. 1). Coincident through-water-column profiles of velocity and density were available at five of these moorings. Note that N4B was only used for model validation of the currents.

All of the moorings were subsurface taut line moorings with buoyancy pulling upward on a wire against an anchor to suspend sensors at selected depth intervals over the whole water column. Current magnitude and direction were recorded with upward looking acoustic Doppler current profilers (ADCPs; Teledyne RDI), and density was measured with a variety of instruments (Sea-Bird Electronics SBE37 and SBE39 and VEMCO Minilog II-T) at different vertical resolutions on each mooring (see details in Table 1). Tidal energy conversion rates and the baroclinic energy fluxes were calculated from the density and velocity measurements to determine the generation and propagation processes of the internal tides. According to the Nash et al. (2005) criteria, our sample rates were high enough and we had sufficient coverage of sensors near-surface and near-bottom to guarantee the accuracy of the tidal energy calculations.

\section{c. Numerical simulations}

A three-dimensional (3D) hydrostatic numerical model, the MITgcm (Marshall et al. 1997), was used to calculate the internal tide climatology in the Pilbara region. In addition, we used the model in nonhydrostatic mode for 2D vertical slice experiments with idealized tidal forcing and initial conditions to investigate the role of RITs on LITs, in particular the role of incoming wave phase and amplitude on the shelf barotropic-baroclinic energy conversion.

\section{1) 3D MODEL CONFIGURATION}

Three-dimensional experiments were implemented to compute the internal tide climatology in the Pilbara region. We used Geoscience Australia bathymetry data with a horizontal resolution of $250 \mathrm{~m}$. The horizontal grid spacing was $1000 \mathrm{~m}$ in both the longitudinal and latitudinal directions. The standard model domain consisted of $888 \times 630$ grid cells. To satisfy the mode- 1 to mode- 3 vertical resolution requirements, model vertical layers were spaced in accordance with the hyperbolic tangent function (Stewart et al. 2017) given by 

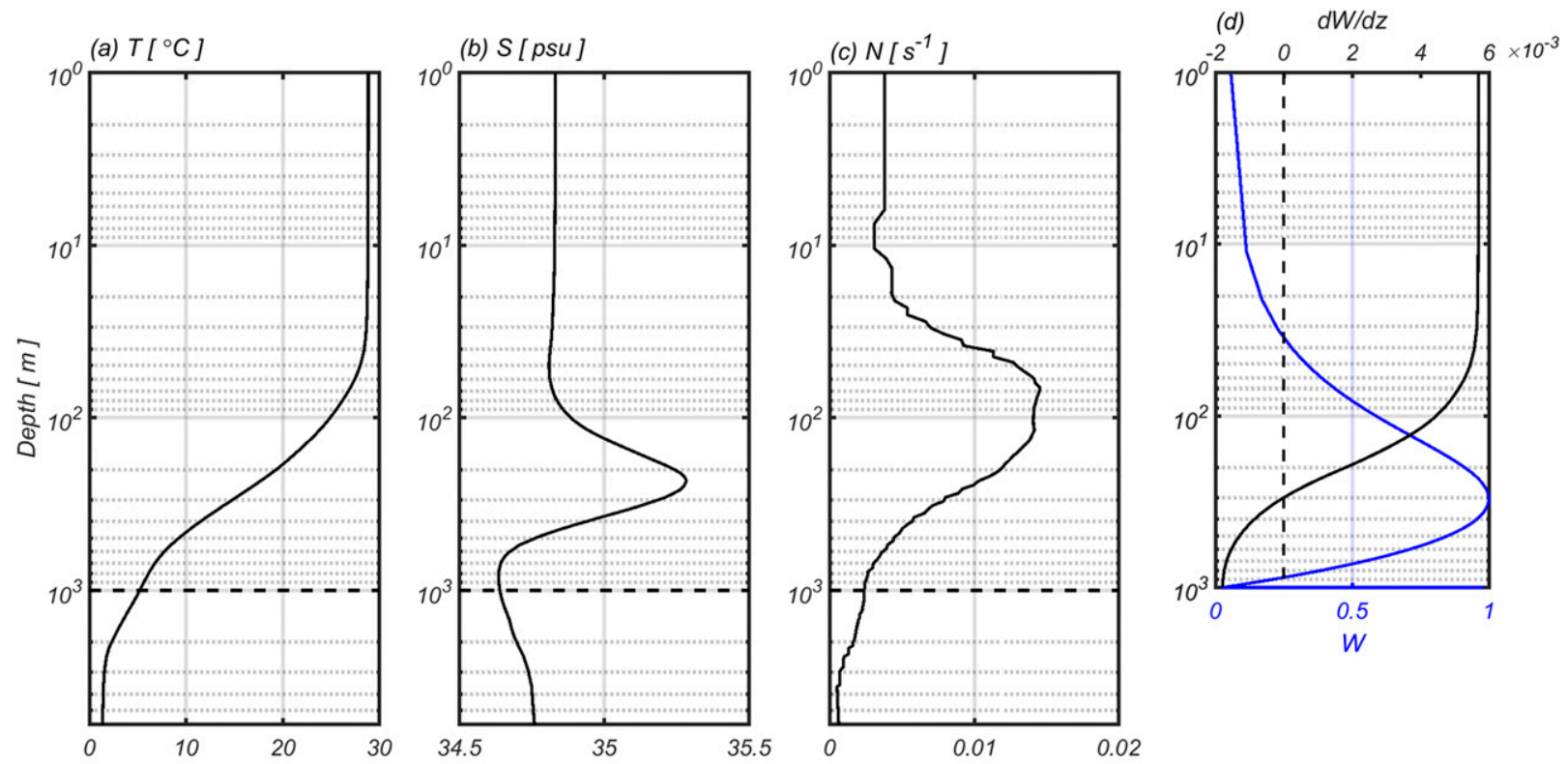

(e) $2 D$ bathymetry

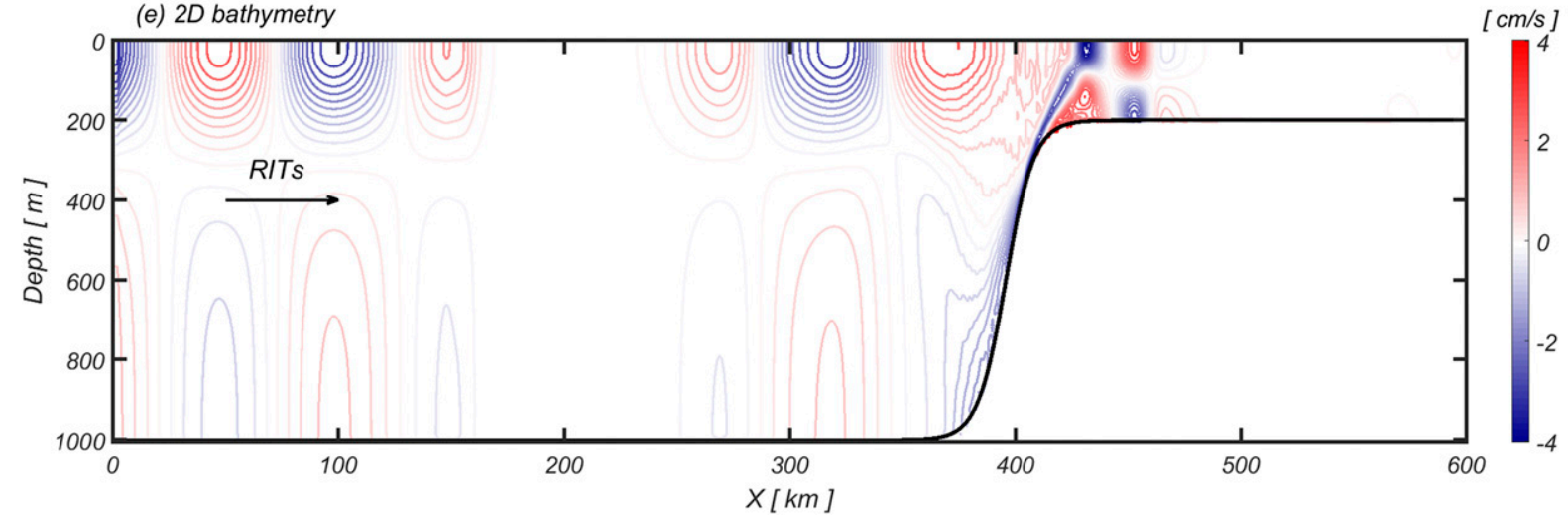

FIG. 2. (a),(b) The initial model temperature and salinity profiles. (c) The profile of buoyancy frequency. The initial stratification for the 2D simulations only extended to $1000 \mathrm{~m}$ (indicated by dashed line). (d) The profile of eigenfunction $W$ (blue) and its vertical gradient (black) based on the initial stratification in the 2D simulations. Note that the $y$ axis in (a)-(d) has a logarithmic scale. (e) A snapshot of the internal tide horizontal velocity field with the idealized 2D bottom topography following the hyperbolic tangent function at $T=20 \mathrm{~h}$. For this example, the arrow represents the incoming baroclinic forcing with the amplitude of $4 \mathrm{~cm} \mathrm{~s}^{-1}$ on the left boundary. The colored contours over the slope represent the baroclinic velocities induced by the interaction between the barotropic tides $\left(1 \mathrm{~cm} \mathrm{~s} \mathrm{~s}^{-1}\right.$ on the left and $5 \mathrm{~cm} \mathrm{~s}^{-1}$ on the right) with the bottom topography.

$$
\Delta z(n)=\Delta z_{\max } \tanh \left(\frac{-n \pi}{s_{h} H_{\max }}\right)+\Delta z_{\min }
$$

where $\Delta z$ is the thickness of each layer; $n$ is the layer number (138 layers); $\Delta z_{\min }$ and $\Delta z_{\max }$ were set as 1 and $100 \mathrm{~m}$, respectively. In the Pilbara region, the maximum depth $H_{\max }$ was $6000 \mathrm{~m}$ and $s_{h}=1.0$ is a dimensionless scaling parameter for adjusting the steepness of the hyperbolic tangent function. The initial model stratification was derived from the Ocean Forecasting Australia Model (OFAM; Oke and Sakov 2008) by temporally and spatially averaging output from April 2012, resulting in horizontally uniform temperature and salinity initial conditions (Figs. 2a-c).

As the semidiurnal barotropic tides are dominant in the Pilbara region, the model was driven by $\mathrm{M}_{2}$ and $\mathrm{S}_{2}$ tides on the boundaries with values taken from the Oregon State University TOPEX/Poseidon Solution (TPXO8-atlas data) with $1 / 30^{\circ}$ resolution (Egbert and Erofeeva 2002). A 50-km-wide sponge layer was imposed on each lateral boundary to absorb internal tides and avoid reflection back to the inner region. We ran a 35-day simulation covering a complete spring and neap tide cycle. Quasi-steady conditions occurred after 10 days, so the model results were analyzed over 
the remaining 25 days. We applied constant horizontal and vertical eddy viscosity and diffusivity coefficients as $A_{h}=10 \mathrm{~m}^{2} \mathrm{~s}^{-1} ; A_{v}=10^{-4} \mathrm{~m}^{2} \mathrm{~s}^{-1} ; K_{h}=$ $10 \mathrm{~m}^{2} \mathrm{~s}^{-1} ; K_{v}=10^{-5} \mathrm{~m}^{2} \mathrm{~s}^{-1}$ to eliminate gridscale instability (Legg and Huijts 2006; Nagai and Hibiya 2015) and parameterized the bottom stress using a quadratic law with $C_{d}=2.5 \times 10^{-3}$.

To evaluate the influence of the western portion of the Exmouth Plateau on the local internal tide climatology on the inner shelf, we undertook two numerical simulations with different computational domains (Fig. 1). The smaller domain did not include the western portion of the Exmouth Plateau. We used the same initial stratification, boundary forcing, viscosity and diffusivity coefficients, and spatial resolution in both model runs.

\section{2) 2D MODEL CONFIGURATION}

The 2D MITgcm experiments were employed to examine the effect of varying amplitude and phase of the RITs on the local energy conversion over the slope and shelf. A horizontal grid scale of $100 \mathrm{~m}$ and a domain of $600 \mathrm{~km}$ were used for the $2 \mathrm{D}$ experiments. The vertical layers were also set following the hyperbolic tangent function profile, with layer thicknesses ranging from $1 \mathrm{~m}$ near the surface to $20 \mathrm{~m}$ near the seabed (maximum $1000 \mathrm{~m}$ ). An idealized hyperbolic tangent bottom topography (Fig. 2e) was used:

$h(x)=\frac{1}{2}\left(H_{0}-H_{s}\right) \tanh \left(\frac{x-x_{s}}{S}\right)-\frac{1}{2}\left(H_{0}+H_{s}\right)$,

where $H_{0}$ is the maximum water depth and $x_{s}$ and $H_{s}$ are the location and water depth on the shelf, respectively. The shelf width $S$ was selected to ensure a critical condition existed at one point on the slope. Values of other 2D model parameters are summarized in Table 2. The $2 \mathrm{D}$ model was driven by a barotropic tide on both lateral boundaries, and the baroclinic RIT was imposed at the left boundary and given by

$$
\begin{aligned}
U_{\text {left }}(z) & =U_{\mathrm{bc}}(z) \cos \left(\omega_{s 2} t-\theta_{\mathrm{bc}}\right)+U_{\mathrm{bt}, \text { left }} \cos \left(\omega_{s 2} t-\theta_{\mathrm{bt}}\right) \\
U_{\text {right }} & =U_{\mathrm{bt}, \text { right }} \cos \left(\omega_{s 2} t-\theta_{\mathrm{bt}}\right)
\end{aligned}
$$

The amplitudes of the barotropic velocities $\left(U_{\mathrm{bt}, \text { left }}\right.$, $\left.U_{\mathrm{bt}, \text { right }}\right)$ were set at the boundaries and the phases were the same value to ensure mass conservation in the domain. A $20-\mathrm{km}$-wide sponge boundary condition was imposed at both lateral boundaries. We varied the RIT amplitude $U_{\mathrm{bc}}(z)$ and phase $\theta_{\mathrm{bc}}$ in a series of idealized 2D runs (BT-BC Exps and High-BC Exps, Table 3). For
TABLE 2. Parameters in the 2D nonhydrostatic MITgcm experiments.

\begin{tabular}{lcc}
\hline \hline \multicolumn{1}{c}{ Parameters } & Notation & Value \\
\hline Horizontal grid scale & $\Delta x$ & $100 \mathrm{~m}$ \\
Vertical grid scale & $\Delta z$ & $1-20 \mathrm{~m}$ \\
Time step & $\Delta t$ & $10 \mathrm{~s}$ \\
Horizontal eddy viscosity coefficient & $A_{h}$ & $10^{1} \mathrm{~m}^{2} \mathrm{~s}^{-1}$ \\
Vertical eddy viscosity coefficient & $A_{v}$ & $10^{-4} \mathrm{~m}^{2} \mathrm{~s}^{-1}$ \\
Horizontal diffusivity coefficient & $K_{h}$ & $10^{1} \mathrm{~m}^{2} \mathrm{~s}^{-1}$ \\
Vertical diffusivity coefficient & $K_{v}$ & $10^{-5} \mathrm{~m}^{2} \mathrm{~s}^{-1}$ \\
Bottom stress & $C_{d}$ & $2.5 \times 10^{-3}$ \\
Steepness parameter & $S$ & $12.5 \mathrm{~km}^{-1}$ \\
Left barotropic velocity amplitude & $U_{\mathrm{bt}, \mathrm{left}}$ & $1 \mathrm{~cm} \mathrm{~s}$ \\
Right barotropic velocity amplitude & $U_{\mathrm{bt}, \text { right }}$ & $5 \mathrm{~cm} \mathrm{~s}$ \\
Shelf break location & $x_{s}$ & $400 \mathrm{~km}$ \\
Water depth on the shelf & $H_{s}$ & $200 \mathrm{~m}$ \\
Domain length & $D_{L}$ & $600 \mathrm{~km}$ \\
Maximum water depth & $H_{0}$ & $1000 \mathrm{~m}$ \\
\hline
\end{tabular}

comparison, we completed a case with no RIT (BT-only Exp) and another with a more accurate representation of the across-shore topography (Real Exp, along red dashed line in Fig. 1).

\section{d. Data analysis}

\section{1) Modal DeCOMPosition}

We decomposed the velocity and buoyancy fields of the RITs into different vertical modes (Gerkema and Zimmerman 2008). In terms of one tidal constituent $(\omega)$ in a continuously stratified ocean, the baroclinic wavefield can be written (e.g., Gerkema and Zimmerman 2008; Buijsman et al. 2010) as the sum of vertical modes (e.g., vertical velocity $w$ ):

$$
w(z, t)=\sum_{n=1}^{\infty} A_{n} \exp (-i \omega t) W_{n}(z) .
$$

For mode $n, A_{n}$ and $W_{n}$ are the vertical amplitude and eigenfunction, respectively. The eigenfunctions were obtained by numerically solving the normal mode equation [Eq. (5)]. We calculated $W_{1}$ to define the vertical structure of the RITs (Fig. 2d). Following Buijsman et al. (2010), we normalized the eigenfunctions for vertical velocity and obtained the eigenfunctions for the horizontal velocity and buoyancy as

$$
\mathcal{U}_{n}(z)=A_{n} \frac{i}{k_{n}} \frac{d W_{n}(z)}{d z}, \quad \mathcal{B}_{n}(z)=-A_{n} \frac{i N^{2}(z)}{\omega} W_{n}(z)
$$

Thus, the vertical profile of the RITs was constructed based on the initial stratification. 
TABLE 3. Barotropic and baroclinic tidal forcing and bottom topography for the 2D model runs.

\begin{tabular}{|c|c|c|c|c|c|}
\hline \multirow[b]{2}{*}{ Experiment } & \multicolumn{2}{|c|}{ Barotropic velocities $\left(\mathrm{cm} \mathrm{s}^{-1}\right)$} & \multirow{2}{*}{$\begin{array}{l}\text { Baroclinic surface } \\
\text { velocities }\left(\mathrm{cm} \mathrm{s}^{-1}\right)\end{array}$} & \multirow[b]{2}{*}{ Baroclinic phase } & \multirow[b]{2}{*}{ Topography } \\
\hline & Left & Right & & & \\
\hline Real Exp & 1 & 13.13 & 0 & 0 & Real \\
\hline BT-BC Exps & 1 & 5 & $2-12$ & $0.25 \pi-2.00 \pi$ & Hyperbolic tangent \\
\hline BT-only Exp & 1 & 5 & 0 & 0 & Hyperbolic tangent \\
\hline High-BC Exps & 1 & 5 & $20-40$ & $0.25 \pi-2.00 \pi$ & Hyperbolic tangent \\
\hline
\end{tabular}

\section{2) TeMPoral DeCOMPOSITION}

Surface tides are highly predictable using the sum of known harmonics (sinusoidal function). Using the same model, internal tides can be divided into two components as well. The first can be interpreted as a series of sinusoidal constituents at the tidal frequencies, which are termed the "coherent constituents" (Nash et al. 2012). For the second component, the amplitudes and phases of the motions can be modulated in time. As this portion of the internal tide behavior is unpredictable via harmonic analysis, these are termed "incoherent constituents."

Since the Pilbara region is dominated by semidiurnal surface tides, the coherent internal tides showed high spectral peaks near the $\mathrm{M}_{2}$ and $\mathrm{S}_{2}$ potentials (not shown). We extracted the contributions to tidal variables, phase locked to the surface tide, in the following way. Three-dimensional model and observed data were first bandpass filtered with the semidiurnal cutoff period $(10-14 \mathrm{~h})$. We fit tidal variables (e.g., $u_{\mathrm{bc}}$ and $p^{\prime}$ ) to the $\mathrm{M}_{2}$ and $\mathrm{S}_{2}$ constituents using a least squares minimization technique. The raw time series was separated into the coherent component, and the remaining portion defined as the incoherent component. Note that since the 2D idealized cases were driven by $\mathrm{S}_{2}$ barotropic and/or baroclinic tides, we omitted the filtering calculations and assumed the $2 \mathrm{D}$ model outputs were all coherent constituents at the $S_{2}$ frequency.

\section{Results}

\section{a. $M_{2}$ surface and internal tide validation}

We computed the barotropic current ellipse from the observed depth-averaged velocity at the six different mooring stations on the continental shelf (Figs. 3a-f). The $\mathrm{M}_{2}$ tidal ellipses were the main focus as they dominate in the Pilbara region (Holloway 1988). The predicted $\mathrm{M}_{2}$ tidal ellipses from the 3D model were generally in good agreement with the field measurements and TPXO8-Atlas dataset, reproducing the major features of the local barotropic tides. The discrepancy between the model, observations and the TPXO8 solution at $\mathrm{N} 3 \mathrm{C}$ likely occurred due to inadequately resolved bathymetry in this region.

The model-predicted $\mathrm{M}_{2}$ baroclinic velocity amplitude was compared with field measurements at the six mooring stations for the upper, middle, and bottom depths (Figs. 3g,h). The correlation coefficients for the amplitude and phase between the predicted and observed values were both greater than 0.8 . In general, $\mathrm{M}_{2}$ tidal features were well predicted in the 3D model giving us confidence in the internal tide calculations presented below.

\section{b. Internal tide energetics}

In the 3D model, large positive conversion rates $\left(\sim 1 \mathrm{~W} \mathrm{~m}^{-2}\right)$ demonstrated that internal tides were generated in regions A, B, and C (Fig. 4a). During the spring tide period, domain-integrated conversion rates were 500,370 , and $260 \mathrm{MW}$ in regions $\mathrm{A}, \mathrm{B}$, and C, respectively.

There were also a number of regions where negative conversion rates occurred (Fig. 4a), with values locally as large in magnitude as the positive conversion rates seen elsewhere. The negative conversion rates were mainly found in the inshore regions (e.g., regions B and C) between the 200- and 400-m isobaths, where the PIL200 mooring was located. The model run with a smaller domain, excluding the Exmouth Plateau, demonstrated that large positive and negative conversion rates still occurred in regions $\mathrm{B}$ and $\mathrm{C}$, with a similar pattern to the standard large domain case (Fig. 4b). However, in the large domain case net energy conversion integrated over regions B and C increased by $13.5 \%$ $(50 \mathrm{MW})$ in the region $\mathrm{B}$ and $8 \%(20 \mathrm{MW})$ in the region $\mathrm{C}$ when the western portion of the Exmouth Plateau was included. Exmouth Plateau thus constructively influences the conversion rate on the southern NWS continental slope.

During the spring tide period, strong baroclinic energy fluxes $\left(>2.0 \mathrm{KW} \mathrm{m}^{-1}\right)$ emanated from regions $\mathrm{B}$ and $\mathrm{C}$, coincident with larger conversion rates (vectors in Fig. 4a). Internal tides mainly propagated in the offshore direction from these regions and the energy fluxes indicated a complicated pattern $\sim 150 \mathrm{~km}$ from the major generation site (region $B$ ), suggesting the formation 
(a) $\mathrm{N} 2 \mathrm{C}$

$\left[114.85^{\circ} \mathrm{E}, 21.26^{\circ} \mathrm{S}\right]$

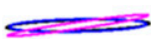

(c) $\mathrm{N} 3 \mathrm{C}$

$\left[115.17^{\circ} \mathrm{E}, 20.19^{\circ} \mathrm{S}\right]$

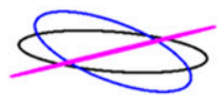

(e) $N 4 B$

$\left[116.07^{\circ} \mathrm{E}, 19.74^{\circ} \mathrm{S}\right]$

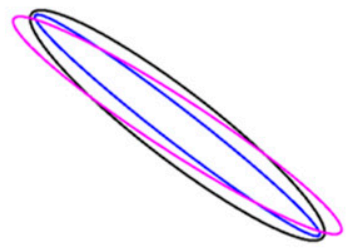

(b) $N I C O P$

$\left[114.63^{\circ} \mathrm{E}, 21.12^{\circ} \mathrm{S}\right]$

(d) $P 100$

$\left[116.11^{\circ} \mathrm{E}, 19.69^{\circ} \mathrm{S}\right]$

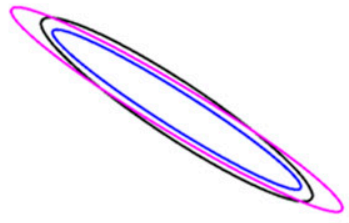

(f) $P 200$

$\left[115.92^{\circ} \mathrm{E}, 19.44^{\circ} \mathrm{S}\right.$ ]

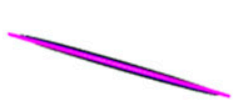

MODEL

OBSERVATION

TPX08-ATLAS

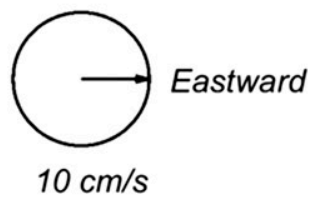

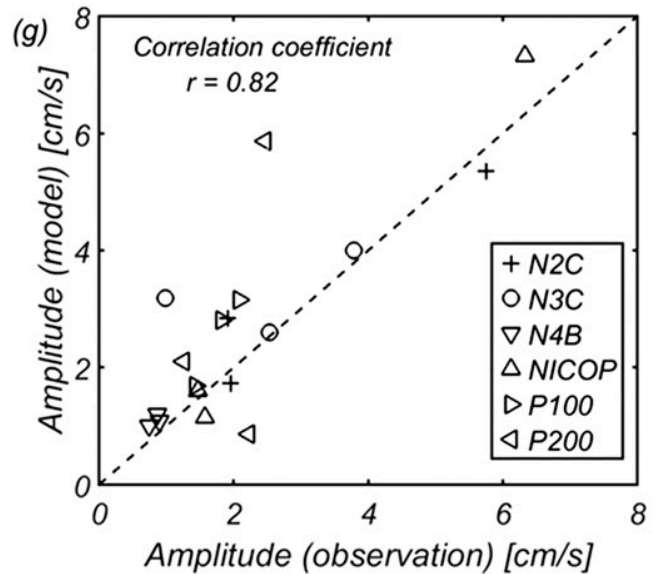

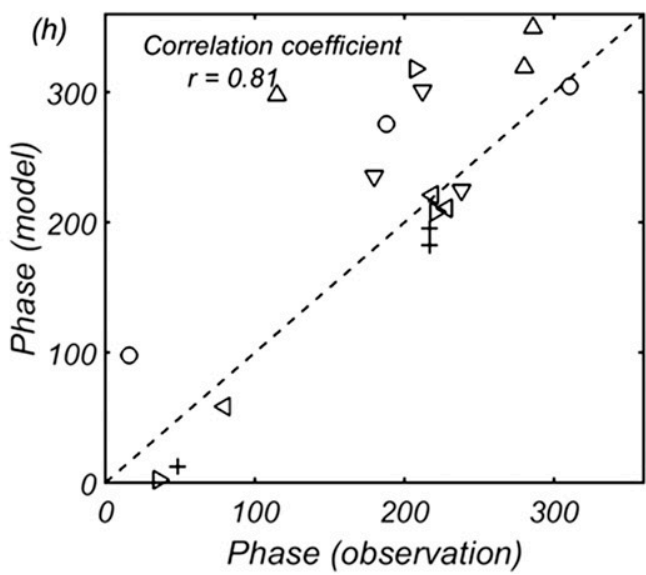

FIG. 3. (a)-(f) Comparison of $\mathrm{M}_{2}$ barotropic current ellipses between the model predictions (black lines), observations (blue lines), and TPXO8-atlas data (red lines) at different moorings. The scale of the ellipse is shown on the right. (g),(h) Scatterplots comparing the $\mathrm{M}_{2}$ baroclinic tidal amplitude and phase between 3D model predictions and observations at six mooring sites.

of standing internal tides due to the interaction between RITs and LITs (e.g., Rayson et al. 2012). However, in the small domain case the energy fluxes primarily propagated northwestward from region $\mathrm{B}$ and then diminished at the west boundary (Fig. 4b), with no suggestion of standing internal tides.

To compare the conversion rate distribution in the large and small domain cases, we calculated the difference between them, and this conversion difference was denoted by $C_{\mathrm{ExP}}$ (Fig. 4c). The magnitude of $C_{\mathrm{ExP}}$ was comparable to the conversion rate $\left(\sim 1.0 \mathrm{~W} \mathrm{~m}^{-2}\right)$ for the standard case. Alternating positive and negative bands of $C_{\mathrm{ExP}}$ can be seen along the isobaths over the slope and perpendicular to the southwest side of the Exmouth Plateau (region A in Fig. 4a), a result of the constructive and destructive interference caused by the varying phase 

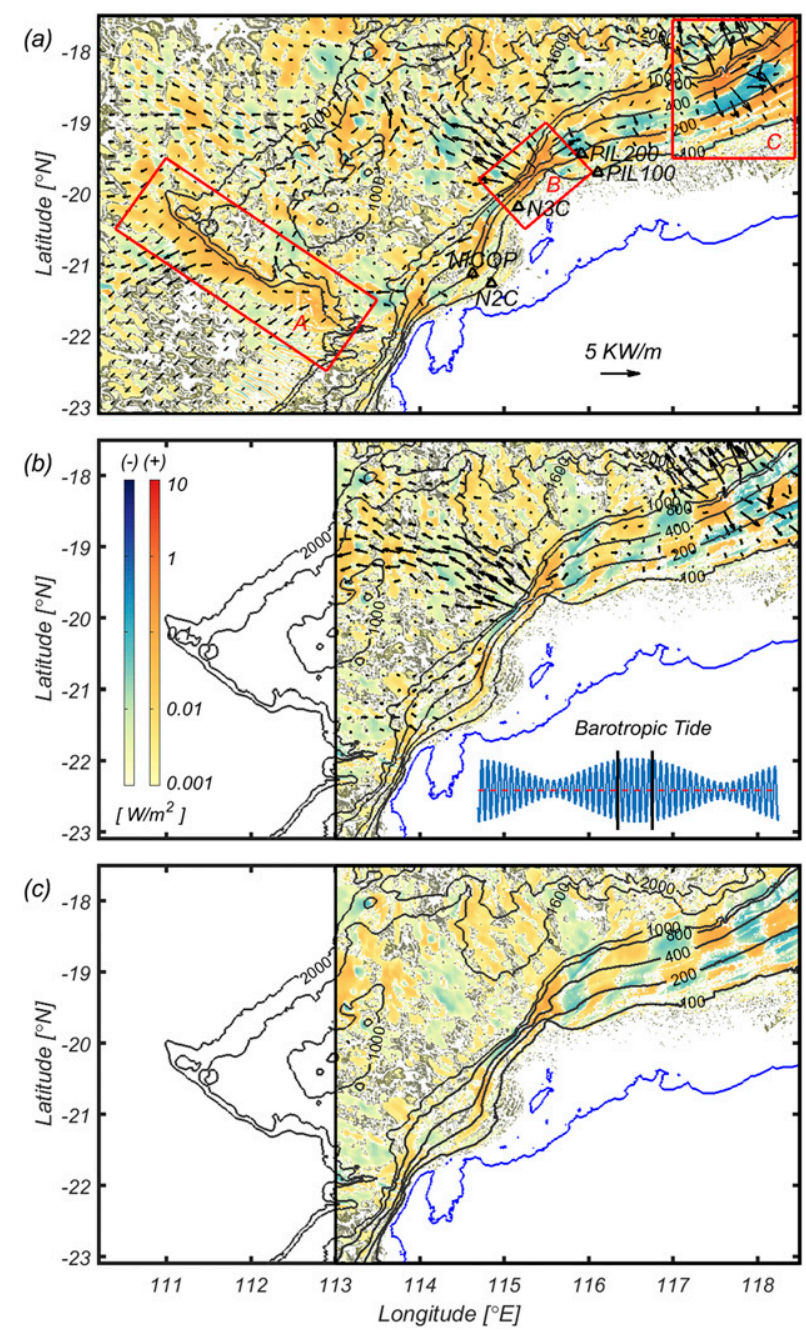

FIG. 4. (a) Spring tide cycle-averaged conversion rates in standard case with the Exmouth Plateau. Vectors mean the depth-integrated tidal-averaged energy flux of baroclinic tides. Three red boxes represent the main generation sites of internal tides. Triangles represent five moorings. (b) The case excluding the western portion of the Exmouth Plateau. (c) Conversion rate difference $C_{\text {ExP }}$ between the standard case and model run excluding the Exmouth Plateau.

difference between the RITs and the LITs throughout the domain [Eq. (9)]. Along the 800-m isobath, the alternating positive and negative $C_{\mathrm{ExP}}$ regions are $\sim 50 \mathrm{~km}$ long, approximately half the wavelength of the mode- 1 baroclinic tide in this water depth.

\section{c. Negative conversion rates}

The semidiurnal coherent conversion rate was estimated from both observations and the model output at five sites. We compared observations and the model at two locations on the 200-m isobath (NICOP and PIL200) and three locations on the 100-m isobath (PIL100, N3C and N2C); the model identified a range of positive and negative conversion rates across these locations. Due to the different deployment periods of the five moorings, model comparisons were undertaken over different time periods (note variable $x$ axes in Fig. 5). Semidiurnal $p^{\prime}$ and $w_{\mathrm{bt}}$ were used to calculate the semidiurnal-coherent conversion rates.

At the NICOP site (Figs. 5a,b), the phase difference between $p^{\prime}$ and $w_{\mathrm{bt}}$ was always much less than $90^{\circ}$, resulting in positive conversion rates in agreement with the model predictions. At the PIL200 site (Figs. 5c,d), $p^{\prime}$ and $w_{\mathrm{bt}}$ were nearly $180^{\circ}$ out of phase, leading to negative conversion rates that were again in agreement with the model predictions.

At the 100-m contour, the PIL100 and N2C sites had a phase difference between $p^{\prime}$ and $w_{\mathrm{bt}}$ ranging from $90^{\circ}$ to $180^{\circ}$, resulting in conversion rates that periodically crossed the zero point. However, both the model results and field data demonstrated the time-averaged conversion rates were positive at these two moorings. A large difference between the model and observations occurred at $\mathrm{N} 3 \mathrm{C}$. Note that the conversion magnitude was one order smaller than most other sites. This disagreement may come from two sources. First, the 3D numerical model does not predict the tidal climatology well at N3C (see Fig. 3) and second; the observed conversion rate may not be predicted well due to a low vertical resolution of the thermistors and inadequate sampling near the surface, as well as the overall short record length leading to errors in the temporal decomposition.

The 2D model (Real Exp) was run with realistic topography along the selected cross section identified from the 3D model (Fig. 1). A small-amplitude barotropic $\mathrm{M}_{2}$ tide was used to force the model to maintain linear conditions (refer to Real Exp in Table 3), resulting in different conversion magnitudes to the $2 \mathrm{D}$ and $3 \mathrm{D}$ cases. There was no RIT in this model run. The slope criticality parameter $\gamma$ (ratio of local wave characteristic slope to bottom slope) along this cross section indicated that near-critical slopes occur at $25 \mathrm{~km}<x<55 \mathrm{~km}$ (Fig. 6c), coincident with the region of large positive conversion (Fig. 6a) and zero phase difference $\left[\cos \left(\theta^{\prime}\right) \approx 1\right]$ (shown in Fig. 6b). The differences in $\theta^{\prime}$ between the 2D and $3 \mathrm{D}$ cases resulted from additional remote generation sites in the 3D case influencing the phase of $p^{\prime}$.

The strongest positive conversion site was located approximately $35 \mathrm{~km}$ from the strongest negative conversion site (Fig. 6a). The mode- 1 phase speed $c_{\mathrm{bc}}=$ $1.5 \mathrm{~m} \mathrm{~s}^{-1}$ between 300 - and $500-\mathrm{m}$ water depth, while the barotropic phase speed was $c_{\mathrm{bt}}=\sqrt{g H}=70 \mathrm{~m} \mathrm{~s}^{-1}$. The propagation time from the main generation site to the site with negative conversion was thus approximately $6.5 \mathrm{~h}$ and $8 \mathrm{~min}$ for the baroclinic and barotropic tides, respectively. The time lag between the mode- 0 

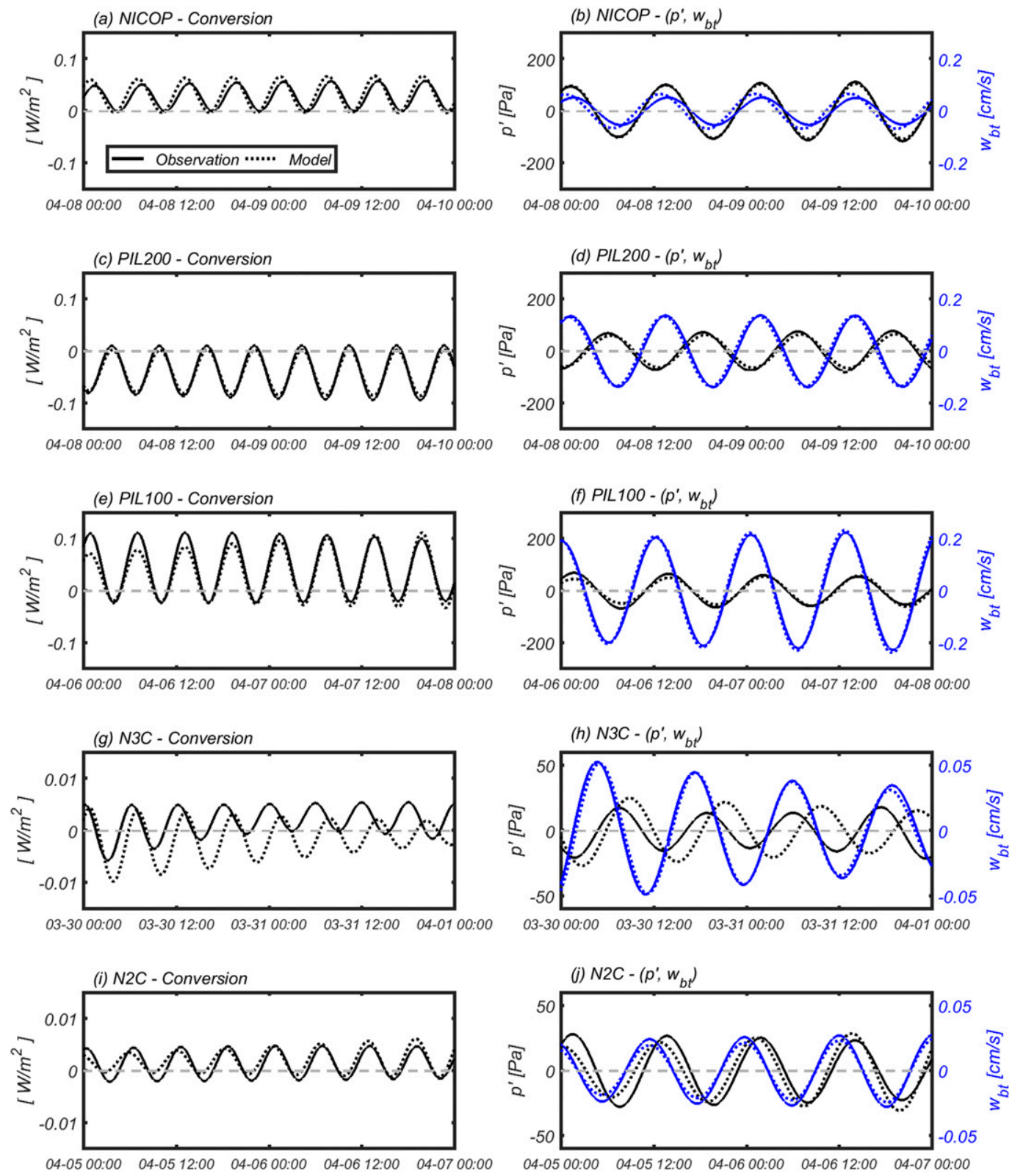

FIG. 5. Semidiurnal coherent conversion at the mooring sites (a) NICOP, (c) PIL200, (e) PIL100, (g) N3C, and (i) N2C during spring tides. Bottom pressure perturbation (black) and vertical barotropic velocity (blue) at the moorings (b) NICOP, (d) PIL200, (f) PIL100, (h) N3C, and (j) N2C. Solid and dotted lines indicate observed and modeled results, respectively. Note that the magnitude of the $y$ axis in (g) and (i) is one order smaller than in (a), (c), and (e).

and mode- 1 tides was thus nearly half of the semidiurnal period, and resulted in $p^{\prime}$ and $w_{\mathrm{bt}}$ being out of phase at this site, leading to negative conversion.

\section{d. Effect of RITs}

The 3D model revealed that the western portion of the Exmouth Plateau was a significant remote generation site that influenced local net energy conversion on the inner shelf and slope. To study the interaction of RITs with LITs, we implemented a series of 2D idealized cases with the amplitude of the baroclinic forcing ranging from 2 to $40 \mathrm{~cm} \mathrm{~s}^{-1}$ and the phase $\left(\theta_{p, r}\right)$ ranging from $0.25 \pi$ to $2.00 \pi$ (BT-BC Exps and HighBC Exps, Table 3).

\section{1) Propagation process}

We first illustrate the spatial variation of the RIT during the propagation process using snapshots of $p_{r}^{\prime}$ for 

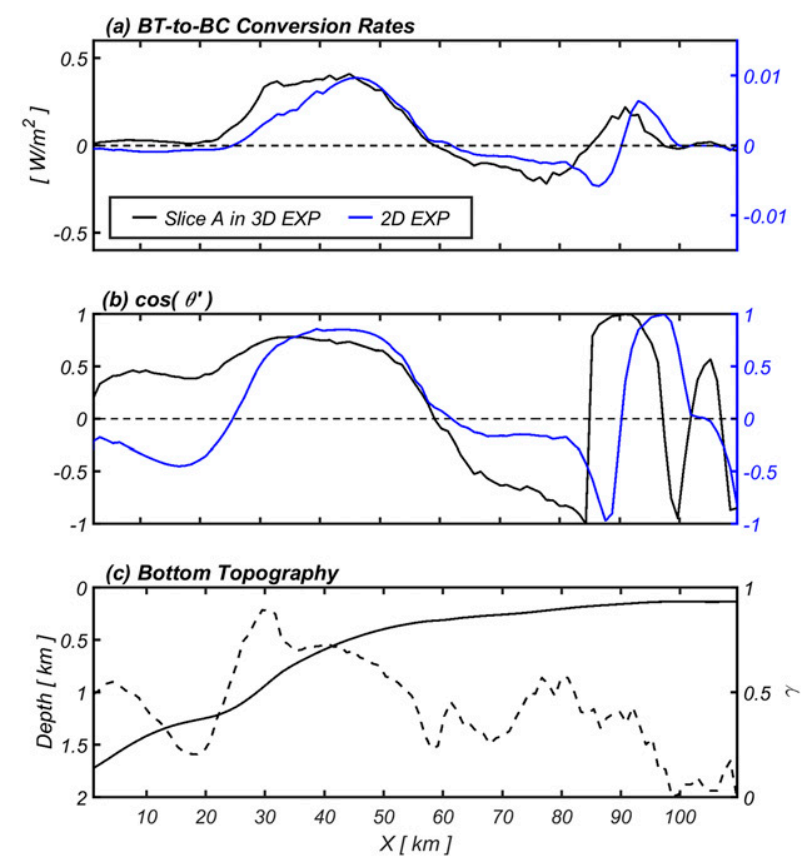

FIG. 6. (a) Tidal-averaged conversion rates and (b) cosine function of the phase difference between the bottom pressure perturbation and vertical barotropic velocity along the cross section for the 3D case (black lines, location shown in Fig. 1) and the $2 \mathrm{D}$ case (blue lines) with single $\mathrm{M}_{2}$ tidal forcing. (c) Bottom topography (black solid line) and topographic critical parameter $\gamma$ (dashed line).

different RIT amplitudes of 4 and $20 \mathrm{~cm} \mathrm{~s}^{-1}$, but both with a constant phase difference of $0.00 \pi$ (Figs. 7a,e). The numerically predicted $p_{r}^{\prime}$ was calculated as the difference between BT-BC Exps and BT-only Exp, while the kinematic model predicted $p_{r}^{\prime}$ was obtained from Eq. (9).

For the $4 \mathrm{~cm} \mathrm{~s}^{-1}$ amplitude forcing case, the amplitude and phase of the model and kinematic predictions $p_{r}^{\prime}$ [calculated using Eq. (2)] were in good agreement in deep water, demonstrating the interaction was a linear process. For the $20 \mathrm{~cm} \mathrm{~s}^{-1}$ forcing case, model and kinematic predictions were in agreement for the early stage from 0 to 40 model hours. After $40 \mathrm{~h}(x>300 \mathrm{~km})$, the leading edge of the numerically predicted RITs steepened and became strongly nonlinear, thus deviating from the linear kinematic predictions (Fig. 7e).

\section{2) Phase speeds And PRopagation time}

The phase of RITs can be expressed as $\theta_{\mathrm{bc}, r}=\left[\theta_{p, r}+\right.$ $\left(T_{p} / T_{\mathrm{bt}}\right) 2 \pi$ ] [Eq. (3)], thereby the propagation time of RITs can affect the sign of $C_{r}$ [Eq. (9)]. To consider the propagation time of RITs, we first estimated both the linear and numerical model phase speeds. The mode-1 linear phase speed $c_{\mathrm{th}}$ was derived from Eq. (5), which was approximately $2.4 \mathrm{~m} \mathrm{~s}^{-1}$ in deep water (shown in blue dashed lines in Figs. 7b,f). We then traced the troughs of RITs and calculated the numerically predicted phase speed $c_{\text {mod }}$ (shown in black lines in Fig. 7b). For the $4 \mathrm{~cm} \mathrm{~s}^{-1}$ amplitude forcing case, $c_{\text {mod }}$ varied slightly with distance, but kept in close agreement with $c_{t h}$. In contrast, the deviation between $c_{\text {mod }}$ and $c_{\text {th }}$ was significant for the $20 \mathrm{~cm} \mathrm{~s}^{-1}$ amplitude case.

Based on the numerically predicted phase speeds in deep water, the RIT propagation time per grid was obtained over the model domain (Figs. 7c,g). The arrival time of RITs was $\sim 40$ and $\sim 38 \mathrm{~h}$ for the 4 and $20 \mathrm{~cm} \mathrm{~s}^{-1}$ amplitude cases, respectively. The cosine function of the kinematically predicted $\theta_{\text {th }}$ agreed well with numerical prediction $\left(\theta_{\mathrm{bc}, r}\right)$ for the entire model domain for the $4 \mathrm{~cm} \mathrm{~s}^{-1}$ amplitude case. In contrast, for the $20 \mathrm{~cm} \mathrm{~s}^{-1}$ amplitude case, $\cos \left(\theta_{\mathrm{th}}\right)$ and $\cos \left(\theta_{\mathrm{bc}, r}\right)$ deviated and had different signs at $x=$ $350 \mathrm{~km}$. These deviations resulted from the steepening process of large-amplitude RITs, which are discussed below (section $5 b$ ).

\section{3) Phases And Amplitudes}

The phase of the RIT $\left(\theta_{p, r}\right)$ also contributes to the sign of $C_{r}$. We use the case with an RIT amplitude of $4 \mathrm{~cm} \mathrm{~s}^{-1}$ as an example. When the phase of the RIT was varied, $C_{r}$ over the slope varied from regions with predominantly positive to predominantly negative values (e.g., Figs. 8b,f). Similar positive and negative regions of $C_{r}$ occurred along the isobath on the continental slope in the 3D model (Fig. 4c). Although the center of the slope was $x_{s}=$ $400 \mathrm{~km}$, the topography was subcritical at this location. The near-critical point on the slope was located around $x=405 \mathrm{~km}$, where we find both the minimum (Fig. 8h) and maximum values of $C_{r}$ (Fig. 8d). Numerical and kinematic predictions of $C_{r}$ were in good agreement (blue and black lines in Fig. 8).

We compared the model $C_{r}$ from the 2D idealized simulations with the kinematic predictions [Eq. (9)] at the critical point for a range of different RIT amplitudes and phases (Fig. 9). The kinematic model reproduced the simulation results well, with $C_{r}$ exhibiting a sinusoidal relationship with the baroclinic phase. For the kinematic prediction, $C_{r}$ should have a linear relationship with the RIT amplitude [according to Eq. (9)], which was in agreement with the model predictions when the baroclinic amplitude ranged from 2 to $4 \mathrm{~cm} \mathrm{~s}^{-1}$. However, when the amplitude increased to above $6 \mathrm{cms}^{-1}$, the linear 
(a) $U_{0}=4 \mathrm{~cm} / \mathrm{s}[\mathrm{Fr}=0.017]$
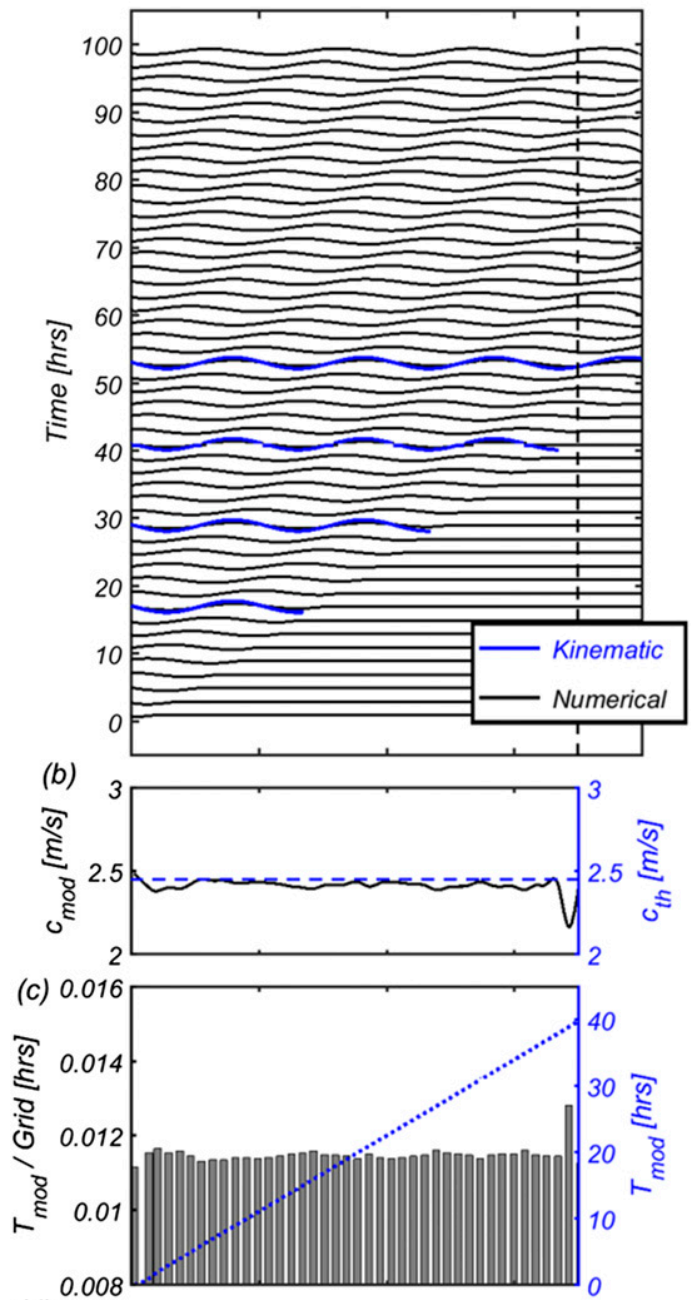

(d)

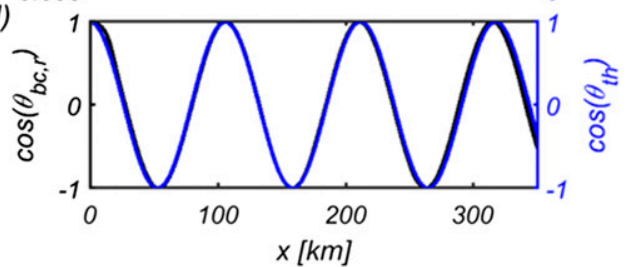

(e) $U_{0}=20 \mathrm{~cm} / \mathrm{s}[\mathrm{Fr}=0.084]$
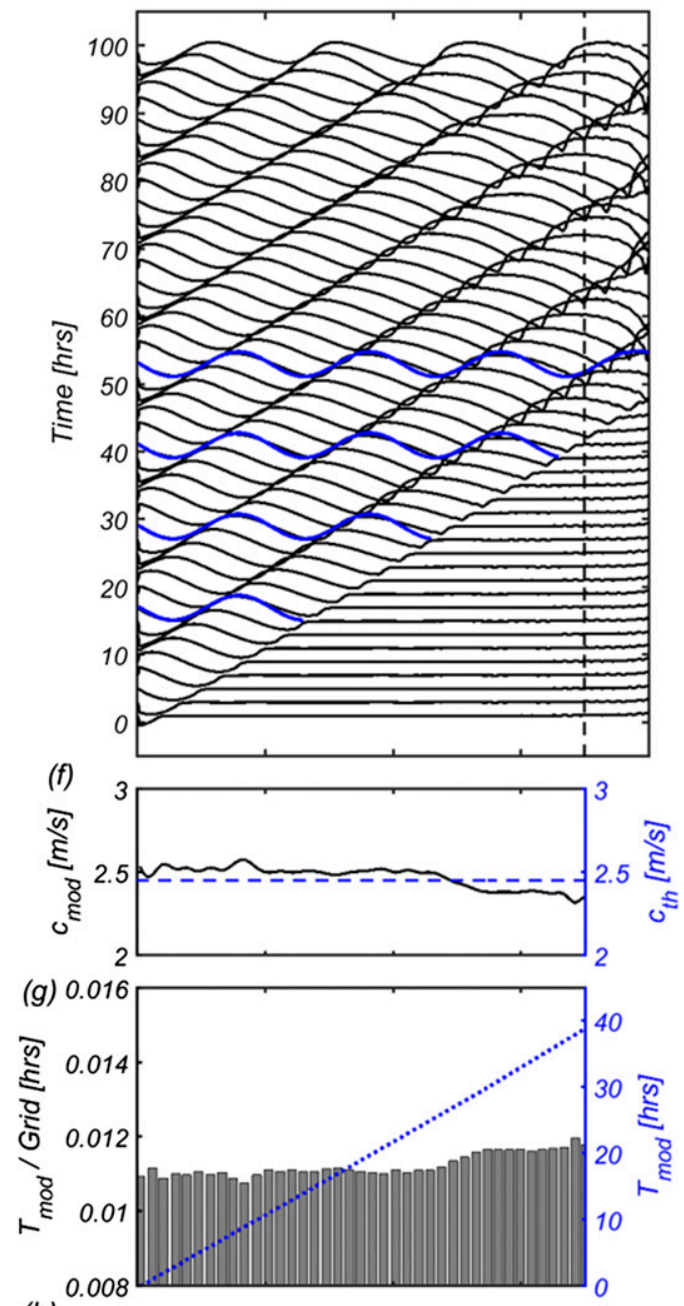

(h)

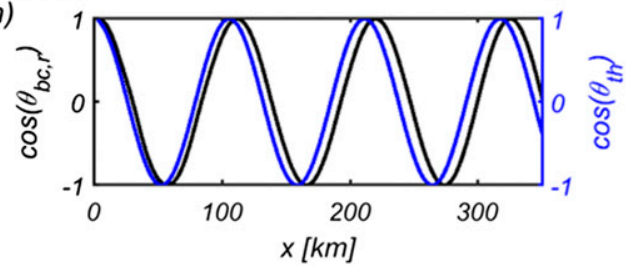

FIG. 7. (a) Snapshots of $p_{r}^{\prime}$ for cases with $4 \mathrm{~cm} \mathrm{~s}^{-1}$ velocity $(\mathrm{Fr}=0.017)$ on the left boundary at times from 0 to $100 \mathrm{~h}$. The black dashed line is the edge of continental shelf. Blue lines indicate the kinematic prediction of $p_{r}^{\prime}$. (b) The black solid line represents numerically predicted phase speed while the blue dashed line is theoretical linear phase speed. (c) The bar graph shows the propagation time of numerically predicted RITs across a single grid point $(100 \mathrm{~m})$; the blue dotted line is the accumulated propagation time along the model domain. (d) The cosine function of numerically predicted $\theta_{\mathrm{bc}, r}$ [refer to Eq. (3)] is shown with the black line, while the cosine function of theoretical $\theta_{\text {th }}$ is the blue line. (e)-(h) As in (a)-(d), but for the cases with initial velocity amplitudes of $20 \mathrm{~cm} \mathrm{~s}^{-1}(\mathrm{Fr}=0.084)$.

kinematic model slightly overpredicted $C_{r}$ at the critical point.

To compare the kinematic predictions with the model results, we added an additional $x$ axis with $\theta^{\prime}$ [see Eq. (9)] and nondimensionalized the $y$ axis with $C_{l}$, the conversion rate at $x=405 \mathrm{~km}$ in the BTonly case (Fig. 9). The peak of the nondimensional $C_{r}$ occurred when $\theta^{\prime}$ was $8.0 \pi$, or four complete wave cycles. Parameter $C_{r}$ thus varied sinusoidally with the phase of the RITs, and varied linearly with 

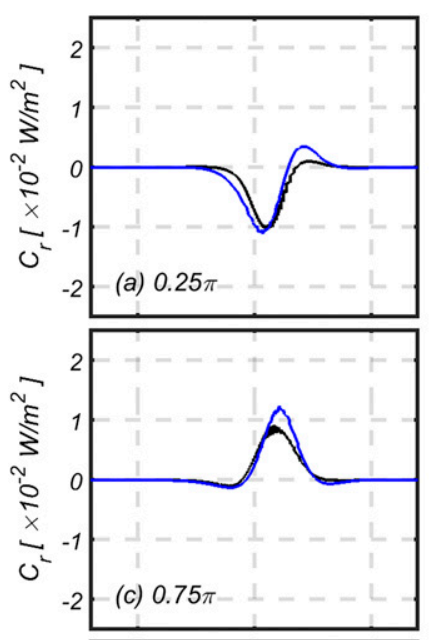

(b)
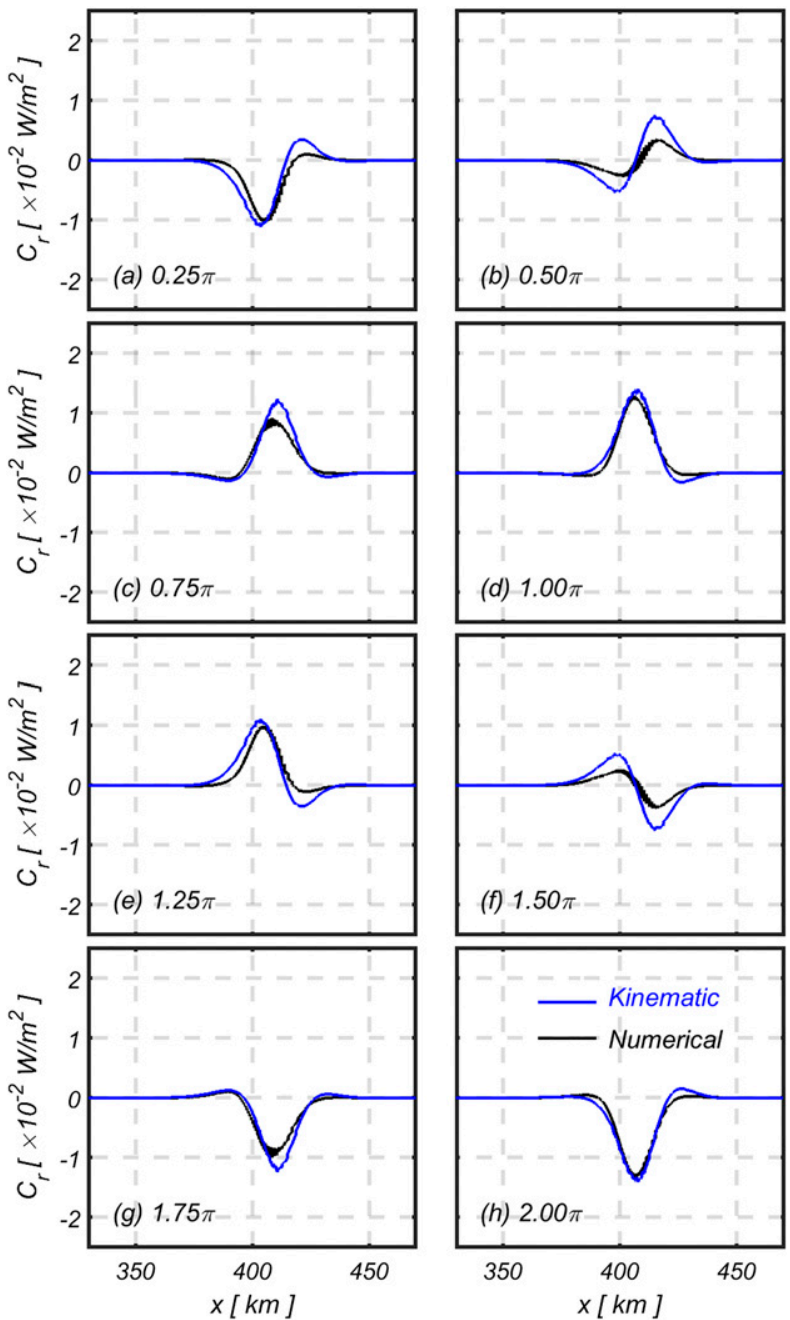

FIG. 8. The $4 \mathrm{~cm} \mathrm{~s}^{-1}$ baroclinic tide amplitude case with baroclinic tide phase $\theta_{p, r}$ ranging from $0.25 \pi$ to $2.00 \pi$ at an interval of $0.25 \pi$. (a)-(h) Cycle-averaged $C_{r}$ over the slope for different $\theta_{p, r}$. Black and blue lines represent model estimates and kinematic predictions, respectively.

the amplitudes of RITs for low-amplitude forcing cases.

\section{Discussion}

Historically, internal tide climatology on shelf regions has been estimated using regional models, under the assumption that local internal tide generation is dominant (e.g., Holloway 1996). As model domains are increased, a significant effect of far-field generation sites on local energy conversion is often observed. Here we found that on the southern NWS, net energy conversion was $11 \%(0.22 \mathrm{GW})$ smaller when the model domain excluded the (remote) western portion of the Exmouth Plateau (Fig. 4b). This is the net

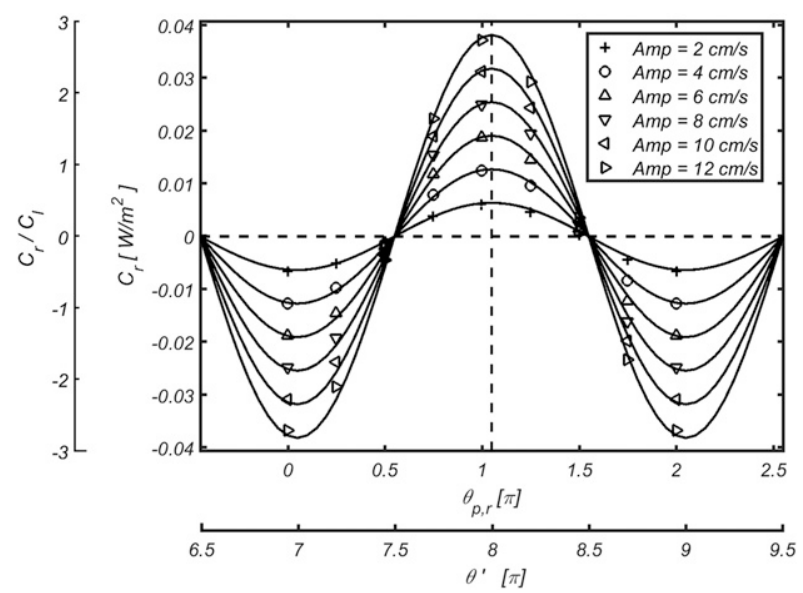

FIG. 9. Parameter $C_{r}$ at the location $x=405 \mathrm{~km}$ with the baroclinic forcing phase ranging from 0 to $2.00 \pi$ and amplitude ranging from 2 to $12 \mathrm{~cm} \mathrm{~s}^{-1}$. Markers and lines are numerical modeling and kinematic predictions, respectively. The two $x$ axes are the phase of the RITs $\left(\theta_{p, r}\right.$ and $\left.\theta^{\prime}\right)$, while the two $y$ axes are $C_{r}$ and nondimensional $C_{r}$ scaled by the local conversion rate $C_{l}$ in the case of only barotropic tidal forcing.

result of a $0.34 \mathrm{GW}$ decrease in positive conversion, and a $0.12 \mathrm{GW}$ decrease in negative conversion. This is comparable to the total internal tide generation reduction of $13 \%$ ( or $7.1 \mathrm{MW}$ ) when the outlying bathymetric features were excluded from a model of the Monterey Bay region (Hall and Carter 2011). In contrast, Kerry et al. (2013) estimated that, in the absence of RITs, domain-integrated conversion rates were $11 \%$ greater at the Luzon Strait and $65 \%$ greater at the Mariana Arc.

Our results demonstrate that for small-amplitude tides the phase of RITs is responsible for the changes in local energy conversion, agreeing with previous studies (e.g., Kelly and Nash 2010; Zilberman et al. 2011). However, we have demonstrated that as the amplitude of the RITs increased the changes in the local energy conversion also become dependent on the nonlinearity of the propagating RIT.

\section{a. Remotely influenced conversion rates versus Froude number}

The sensitivity of $C_{r}$ to the forcing amplitude can be described by considering the Froude number (Fr)

$$
\mathrm{Fr}=\frac{U_{\mathrm{bc}}}{c_{p}}
$$

where $c_{p}$ is the mode- 1 linear phase speed [Eq. (5)]. Five locations $(x / L=0.45,0.5,0.55,0.6$ and 0.65$)$ over the shelf were selected to show the horizontal distribution of nondimensional $C_{r}$ (Figs. 10a-e; both numerical and kinematic predictions) at different sites with different 

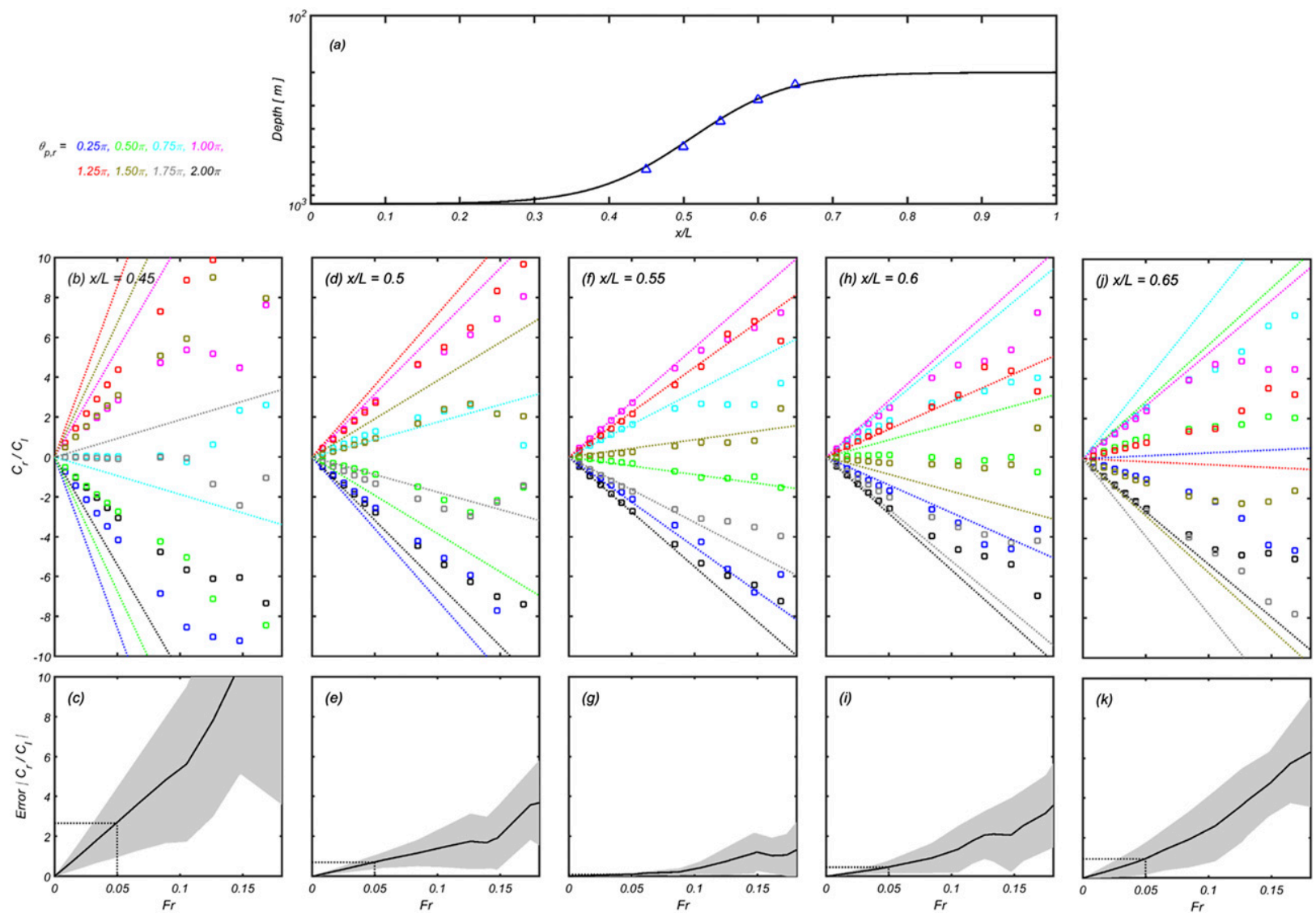

FIG. 10. (a) Bottom topography over the shelf ( $L$ is the shelf length). Blue triangles represent five locations shown in panels below. (b) Nondimensional $C_{r}$ at location $x / L=0.45$ as a function of the RIT wave Froude number. Dots and dashed lines represent the numerical model and kinematic predictions, respectively. Different colors represent different phases of the RITs. (d),(f),(h),(j) As in (b), but at locations $x / L=0.5,0.55,0.6$, and 0.65 . (c) Gray shading is the deviation of $C_{r}$ between the numeric model and kinematic predictions nondimensionalized by local conversion rate $C_{l}$ for different phases. Black lines represent phase-averaged error. Dotted rectangles indicate the small Froude number zone $(\mathrm{Fr}<0.05)$. (e),(g),(i),(k) As in (c), but at locations $x / L=0.5,0.55,0.6$, and 0.65 .

criticalities (blue triangles in Fig. 10a). Note that the critical point was located at $x / L=0.55$. The different phases of RITs play a key role in the sign of the nondimensional $C_{r}$ as well as the magnitude of Fr.

The subcritical topographic features occurred at the location $x / L=0.45$. Taking $4 \mathrm{~cm} \mathrm{~s}^{-1}$ baroclinic tides as an example, numerical $C_{r}$ at the subcritical location $(x=$ $395 \mathrm{~km}$ ) had a small value $\sim O\left(10^{-3}\right) \mathrm{Wm}^{-2}$ and slightly diverged from the kinematic $C_{r}$ (e.g., Figs. 8a,e). In addition, the topographic gradient was small, resulting in a small vertical barotropic velocity $w_{\mathrm{bt}}$ and thereby a small value of local conversion $C_{l}=p_{l}^{\prime} w_{\mathrm{bt}}\left(\sim 2.0 \times 10^{-3} \mathrm{~W} \mathrm{~m}^{-2}\right)$. The nondimensionalized value $C_{r} / C_{l}$ thus accentuated the magnitude of the deviation between the numerical and kinematic predictions at the subcritical locations (shown in Fig. 10b).

At the other subcritical location $(x / L=0.65)$ on the right portion of the shelf, the phase difference between the numerical and kinematic predictions was increasing as the RIT was steepening (e.g., Fig. 7h) and shoaling on the shelf. Therefore, a slight phase difference between the numerical and kinematic predictions can cause the opposing sign as well as a great difference in magnitude between the nondimensionalized numerical and kinematic predictions (shown in Fig. 10j).

In contrast, near-critical and critical points $(x / L=0.5$, 0.55 , and 0.6 ) indicated better agreement between the numerical and kinematic predictions, irrespective of the baroclinic phase. When $\mathrm{Fr}<0.05$, the model and the kinematic predictions agreed well, but for $\mathrm{Fr}>0.05$ the two predictions diverged. To quantitatively demonstrate the difference between the numerical and kinematic predictions, we nondimensionalized the difference of $C_{r}$ with $C_{l}$ (Figs. 10c,e,g,i,k). For subcritical points $x / L=$ 0.45 and 0.65 , the phase-averaged error of $C_{r}$ was always smaller than 2.5 when $\mathrm{Fr}<0.05$. When $\mathrm{Fr}>0.05$, the error kept rising as Fr increased (e.g., Fig. 10c). On the other hand, the critical and near-critical points $(x / L=0.5,0.55$, and 0.6) showed much smaller 
deviations between the two predictions from the two methods. The phase-averaged error was smaller than 1.0 when $\mathrm{Fr}<0.05$ (Figs. 10e,g,i).

RITs with $\mathrm{Fr}=0.017$ and 0.169 were selected to compare $C_{r}$ over the slope in low- and high-wave Froude number cases (Figs. 11b,c). Both positive and negative $C_{r}$ occurred over the shelf for different RIT phase. The linear RITs with low Fr remained linear during propagation, resulting in a smoothly varying pattern of $C_{r}$ over the shelf (e.g., Fig. 11b). However, the RITs with high Fr nonlinearly steepened and lead to an abruptly varying pattern of $C_{r}$ over the shelf (Fig. 11c).

\section{b. Steepening processes of RITs}

As mentioned above, small-amplitude and largeamplitude RITs showed different wave shape developments during the propagating processes on the flat bottom (e.g., Fig. 7a,e), eventually inducing linear and highly nonlinear $C_{r}$ (Figs. 11b,c), respectively. Hence, the purpose of this section is to quantify the differences between the steepening processes of smallamplitude and large-amplitude RITs.

To estimate the ability for an initial RIT to evolve into nonlinear internal waves (NLIWs) during a given propagation time $T_{p}$, we presented the nondimensional steepening parameter $\lambda_{s}$

$$
\lambda_{s}=\frac{T_{p}}{T_{s}} .
$$

Here the steepening time $T_{s}$ can be expressed as $T_{s} \sim l / \alpha A_{0}$ (Horn et al. 2001), arising from balancing the dispersion and nonlinear terms in the Korteweg-de Vries (KdV) equation. Here $l$ and $A_{0}$ are the wavelength and amplitude of the initial RIT, respectively, and $\alpha$ is the nonlinearity coefficient derived from the $\mathrm{KdV}$ equation, which is given by

$$
\alpha=\frac{3 c_{p} \int_{-H}^{0} W_{z}^{3} d z}{2 \int_{-H}^{0} W_{z}^{2} d z} .
$$

For small RITs $(\mathrm{Fr}<0.05)$, the steepening parameter $\lambda_{s}$ was smaller than 1 over the entire model domain $(600 \mathrm{~km})$, hence NLIW steepening could not occur, and thus is why the linear kinematic prediction did well for this small forcing. When large-amplitude RITs ( Fr > 0.08) propagated from the left boundary to the slope, however, $\lambda_{s}$ was greater than 1 , the RITs lost their linear sinusoidal character and the wave fronts steepened. Thus, $p_{r}^{\prime}$ loses the phase coherence (e.g., Fig. 7e) and the kinematic model could no longer accurately predict $C_{r}$.

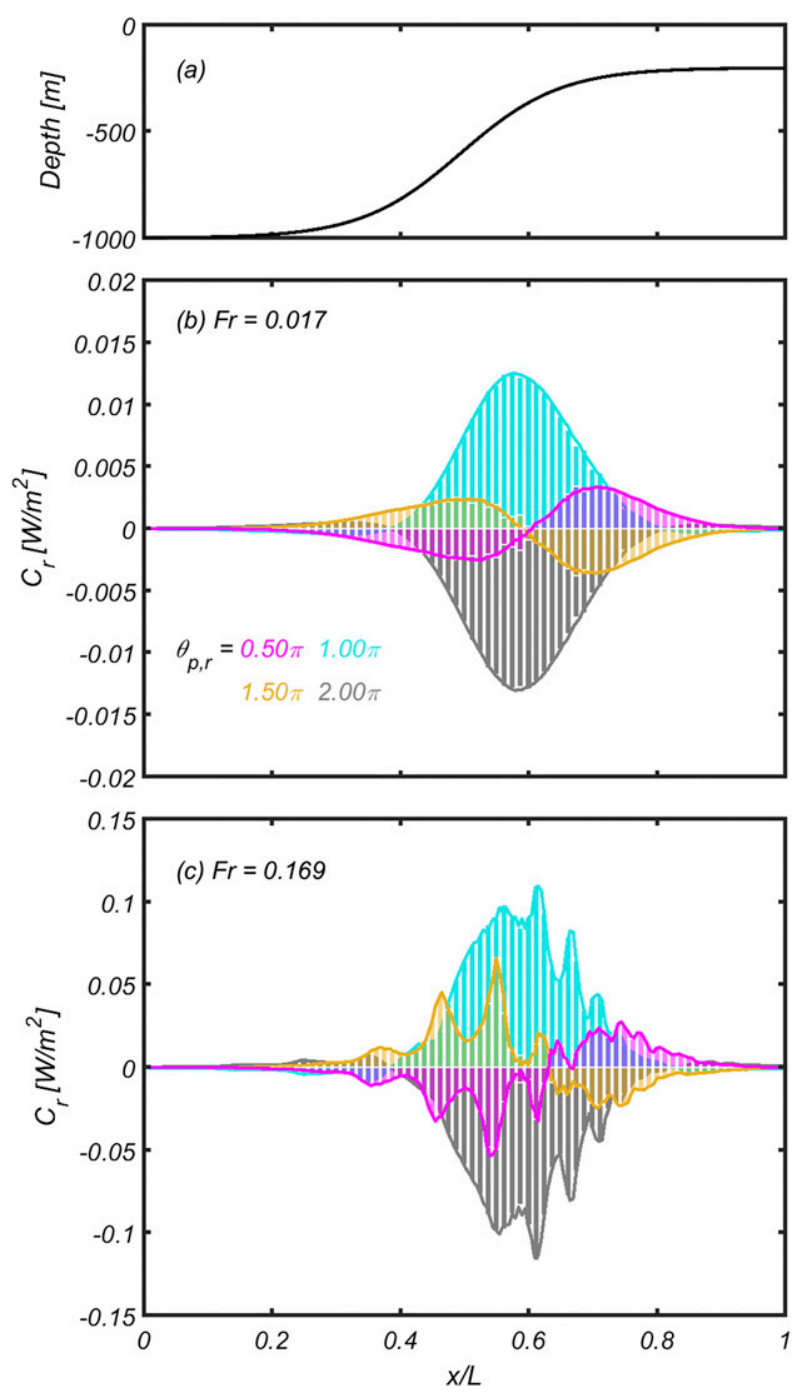

FIG. 11. (a) Bottom topography over the shelf. (b) Histograms are the horizontal distribution of $C_{r}$ over the shelf in the case with low Froude number $(\mathrm{Fr}=0.017)$. Magenta, cyan, yellow, and gray colors represent cases with the remote phase $\theta_{p, r}$ of $0.50 \pi, 1.00 \pi$, $1.50 \pi$, and $2.00 \pi$, respectively. (c) As in (b), but for high Froude number $(\mathrm{Fr}=0.169)$.

Nonlinear effects due to different slope criticalities can also play a role on the effect of RITs (see appendix). Our results show that there is not only a linear effect of RITs on slope generation due to phase interference but also a nonlinear effect that is dependent on the RIT amplitude. Both effects should be considered when calculating barotropic to baroclinic conversion rates over topography in the real ocean.

\section{Conclusions}

The superposition of multiple internal tides results in a complicated internal tide climatology. The southwest part 
of the offshore Exmouth Plateau showed large barotropicto-baroclinic conversion rates and, by running the $3 \mathrm{D}$ model in a reduced domain which excluded the Exmouth Plateau, we demonstrated the internal tides emanating from the Exmouth Plateau played a key role in the internal tide processes on the inshore continental slope and shelf. A comparison of model predictions with observational data at five moorings on the continental shelf revealed both positive and negative local barotropic-to-baroclinic conversion rates as a result of the influence of these remotely generated internal tides.

To quantitatively explain how the RITs influence the LITs on the shelf, we performed a series of 2D model runs with idealized topography and barotropic tidal forcing at a single forcing frequency. The model demonstrated how that local internal tide climatology was modulated by varying phases and amplitudes of RITs. The principle results were as follows:

(i) Phase differences between $p_{r}^{\prime}$ and local $w_{\mathrm{bt}}$ induced both positive and negative conversion rates over the shelf.

(ii) RITs with low Froude number $(\mathrm{Fr}<0.05)$ had steepening length scales greater than the model domain length and thus retained their linear characteristics. The RITs linearly influenced the LIT generation processes, resulting in a smoothly varying pattern of $C_{r}$ over the shelf (e.g., Fig. 11b), and the numerically simulated $C_{r}$ were consistent with kinematic predictions.

(iii) For RITs with high Froude number $(\mathrm{Fr}>0.05)$, the steepening length scale was smaller than the domain length. Due to the increasing nonlinearity, the arrival time of the wave front sharply altered on the shelf, and $C_{r}$ showed a strongly varying pattern over the shelf (Fig. 11c).

The local energy conversion was dependent on the distance between the remote generation site and the local generation sites and the phase relationship and the intensity of both the local barotropic tides and the RITs. Our results demonstrate the importance of considering RITs for both selection of field observation sites and model domains, in order to capture all of the significant internal tide climatology. Our results are consistent with those of Carter et al. (2012) and Kelly and Nash (2010) in demonstrating that regional models need to be either forced by global models or be nested in large regional models to accurately predict the local internal tide climatology.

Acknowledgments. This research was supported by the Australian Research Council Industrial Transformation Research Hub for Offshore Floating Facilities
(IH140100012). Yankun Gong was supported by the Chinese Scholarship Council. Field data were obtained from a collaboration between the U.S. Naval Research Laboratory, the University of Western Australia, and the Australian Institute of Marine Science under the project DP 140101322 and N62909-11-1-7058. In addition, the data of PIL100 and PIL200 moorings was from the Integrated Marine Observing System-a national collaborative research infrastructure, supported by the Australian Government. The numerical experiments were supported by resources provided by the Pawsey Supercomputing Centre with funding from the Australian Government and the Government of Western Australia. Observational data are available on the UWA Library Research Repository.

\section{APPENDIX}

\section{Steepening of RITs over Slopes with Varying Criticality}

To examine the effect of varying slope criticality, we considered six cases with different Froude numbers (Fr) and slope steepness. RITs with amplitudes of 4 and $20 \mathrm{~cm} \mathrm{~s}^{-1}$ were selected to vary $\mathrm{Fr}$, and topographic critical parameters $\gamma$ of $0.5,1.0$, and 2.0 were taken as examples of subcritical, critical, and supercritical slopes (see Fig. A1). These six cases were driven solely by RITs. Other configurations were the same as above 2D cases (shown in Table 2).

For cases with low Froude number $(\mathrm{Fr}=0.017)$, RITs retained their sinusoidal form over the entire model domain, regardless of the slope shape (Fig. A1). The arrival location of the RIT trough was quite consistent after the shoaling process over the subcritical and critical slopes. However, the arrival location of the RIT was slightly delayed in the supercritical case. In addition, the magnitude of RITs on the supercritical shelf was approximately $50 \%$ of the magnitude of RITs on the subcritical shelf. For an incident mode-1 internal tide transmitting upon slopes with a topographic height to water depth ratio of 0.8 (as used in this study), Kelly et al. (2013) assumed that the reflection coefficients for subcritical slopes decrease to zero, while the reflection coefficients for supercritical slopes remain nearly constant and nonnegligible. In comparison, linear model and field observations on the continental shelf of the South China Sea indicate $67 \%$ of incoming mode- 1 energy is transmitted up the supercritical slope (Klymak et al. 2011). For our simulations, compared to the subcritical case $(\gamma=$ $0.5), 65 \%$ and $51 \%$ of the incoming mode- 1 linear internal tide was transmitted up the critical $(\gamma=1.0)$ 


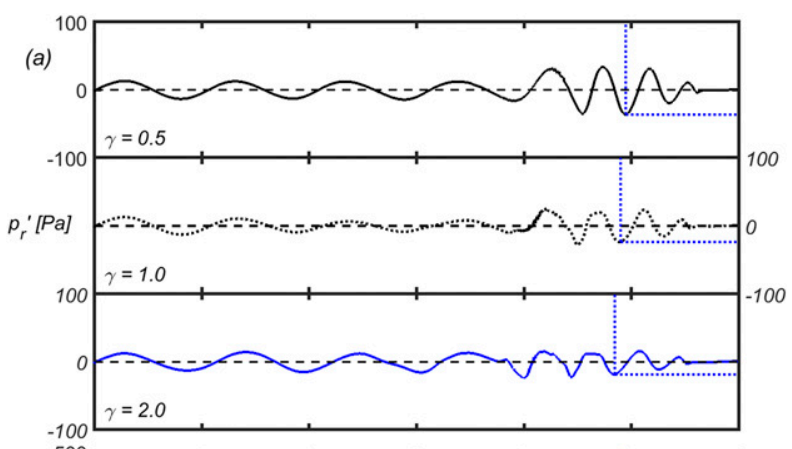

\section{REFERENCES}

Alford, M. H., J. A. MacKinnon, Z. Zhao, R. Pinkel, J. Klymak, and T. Peacock, 2007: Internal waves across the Pacific. Geophys. Res. Lett., 34, L24601, https://doi.org/10.1029/ 2007 GL031566.

Apel, J. R., L. A. Ostrovsky, Y. A. Stepanyants, and J. F. Lynch, 2007: Internal solitons in the ocean and their effect on underwater sound. J. Acoust. Soc. Amer., 121, 695-722, https:// doi.org/10.1121/1.2395914.

Buijsman, M. C., Y. Kanarska, and J. C. McWilliams, 2010: On the generation and evolution of nonlinear internal waves in the South China Sea. J. Geophys. Res., 115, C02012, https:// doi.org/10.1029/2009JC005275.

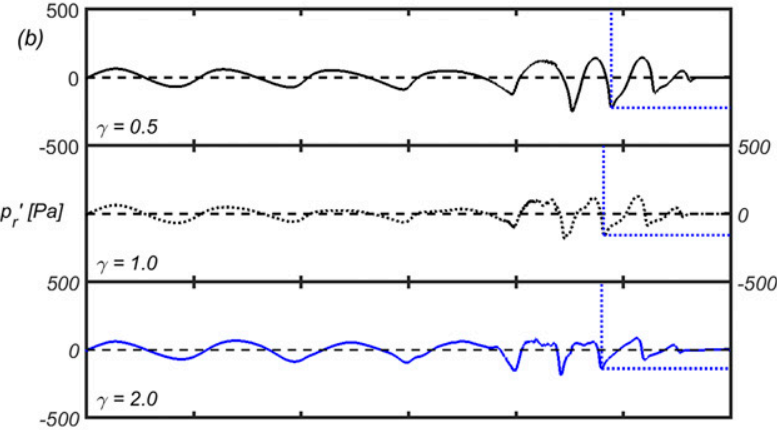

-, S. Legg, and J. Klymak, 2012: Double-ridge internal tide interference and its effect on dissipation in Luzon Strait. J. Phys. Oceanogr., 42, 1337-1356, https://doi.org/10.1175/JPO-D-110210.1.

Carter, G. S., O. B. Fringer, and E. D. Zaron, 2012: Regional models of internal tides. Oceanography, 25 (2), 56-65, https:// doi.org/10.5670/oceanog.2012.42.

Egbert, G. D., and S. Y. Erofeeva, 2002: Efficient inverse modeling of barotropic ocean tides. J. Atmos. Oceanic Technol., 19, 183-204, https://doi.org/10.1175/1520-0426(2002) 019<0183:EIMOBO > 2.0.CO;2.

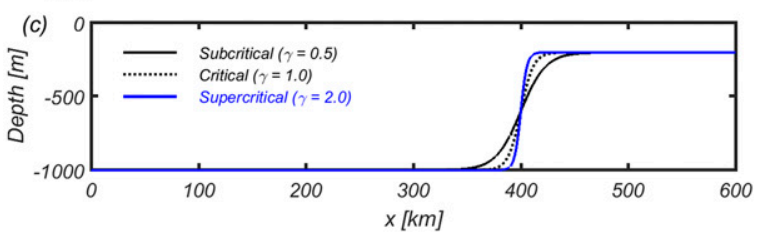

Garrett, C., and E. Kunze, 2007: Internal tide generation in the deep ocean. Annu. Rev. Fluid Mech., 39, 57-87, https://doi.org/ 10.1146/annurev.fluid.39.050905.110227.

Gerkema, T., and J. T. F. Zimmerman, 2008: An introduction to internal waves. Lecture Notes, Royal NIOZ, 207 pp.

Hall, R. A., and G. S. Carter, 2011: Internal tides in Monterey submarine canyon. J. Phys. Oceanogr., 41, 186-204, https:// doi.org/10.1175/2010JPO4471.1.

FIG. A1. (a) A snapshots of $p_{r}^{\prime}$ for the case with RIT amplitude of $4 \mathrm{~cm} \mathrm{~s}^{-1}(\mathrm{Fr}=0.017)$ at the time of $t=96 \mathrm{~h}$. Slopes with topographic critical parameter $\gamma$ of $0.5,1.0$, and 2.0 are shown in the upper, middle, and bottom panels. Blue dotted lines indicate arrival locations and amplitudes of RITs over the slope. (b) As in (a), but for $20 \mathrm{~cm} \mathrm{~s}^{-1}$ RIT amplitude $(\mathrm{Fr}=0.084)$. (c) Bottom topography with subcritical, critical, and supercritical slopes.

and supercritical slopes $(\gamma=2.0)$, respectively. However, the ratio of the topographic height to the water depth is quite different between our model runs (0.8) and the Klymak et al. (2011) observations (0.5), therefore a difference is anticipated.

For cases with high Froude number $(\mathrm{Fr}=0.084)$, RITs retained their sinusoidal form from $x=$ $0-150 \mathrm{~km}$, and steepened at $x=200 \mathrm{~km}$, becoming increasingly nonlinear after that (Fig. A1). The RITs steepened at different rates over the different slopes. At $t=96 \mathrm{~h}$, the RIT arrived at location $x=489,482$, and $480 \mathrm{~km}$ with $p_{r}^{\prime}$ amplitudes of 222, 156, and $137 \mathrm{~Pa}$ over the subcritical, critical and supercritical slope regions, respectively Thereby, $70 \%$ and $62 \%$ of the incoming mode- 1 linear internal tide was transmitted up the critical $(\gamma=1.0)$ and supercritical slopes $(\gamma=2.0)$, respectively. In summary, slope criticality played a large role in the arrival location and amplitude variation of RITs.

Holloway, P. E., 1984: On the semidiurnal internal tide at a shelf-break region on the Australian North West Shelf. J. Phys. Oceanogr., 14, 1787-1799, https://doi.org/10.1175/ 1520-0485(1984)014<1787:OTSITA $>2.0 . \mathrm{CO} ; 2$.

- 1985: A comparison of semidiurnal internal tides from different bathymetric locations on the Australia North West Shelf. J. Phys. Oceanogr., 15, 240-251, https://doi.org/10.1175/ 1520-0485(1985)015<0240:ACOSIT > 2.0.CO;2.

, 1988: Physical oceanography of the Exmouth Plateau region, North-western Australia. Mar. Freshwater Res., 39, 589-606, https://doi.org/10.1071/MF9880589.

__ 1996: A numerical model of internal tides with application to the Australian North West Shelf. J. Phys. Oceanogr., 26, 21-37, https://doi.org/10.1175/1520-0485(1996)026<0021: ANMOIT $>2.0 . \mathrm{CO} ; 2$.

_ model of internal tide transformation on the Australian North West Shelf. J. Phys. Oceanogr., 27, 871-896, https://doi.org/ 10.1175/1520-0485(1997)027<0871:ANMOIT>2.0.CO;2.

_ P. G. Chatwin, and P. Craig, 2001: Internal tide observations from the Australian North West Shelf in summer 1995. J. Phys. Oceanogr., 31, 1182-1199, https://doi.org/10.1175/ 1520-0485(2001)031<1182:ITOFTA $>2.0 . \mathrm{CO} ; 2$.

Horn, D. A., J. Imberger, and G. N. Ivey, 2001: The degeneration of large-scale interfacial gravity waves in lakes. J. Fluid Mech., 434, 181-207, https://doi.org/10.1017/S0022112001003536.

Jones, N. L., and G. N. Ivey, 2017: Internal waves. Encyclopedia of Maritime and Offshore Engineering, J. Carlton, P. Jukes, and Y. S. Choo, Eds., Wiley, https://doi.org/10.1002/ 9781118476406.emoe089. 
Kelly, S. M., and J. D. Nash, 2010: Internal-tide generation and destruction by shoaling internal tides. Geophys. Res. Lett., 37, L23611, https://doi.org/10.1029/2010GL045598.

— , N. L. Jones, and J. D. Nash, 2013: A coupled model for Laplace's tidal equations in a fluid with one horizontal dimension and variable depth. J. Phys. Oceanogr., 43, 17801797, https://doi.org/10.1175/JPO-D-12-0147.1.

Kerry, C. G., B. S. Powell, and G. S. Carter, 2013: Effects of remote generation sites on model estimates of $M_{2}$ internal tides in the Philippine Sea. J. Phys. Oceanogr., 43, 187-204, https:// doi.org/10.1175/JPO-D-12-081.1.

Klymak, J. M., M. H. Alford, R. Pinkel, R. C. Lien, Y. J. Yang, and T. Y. Tang, 2011: The breaking and scattering of the internal tide on a continental slope. J. Phys. Oceanogr., 41, 926-945, https://doi.org/10.1175/2010JPO4500.1.

— M. Buijsman, S. Legg, and R. Pinkel, 2013: Parameterizing surface and internal tide scattering and breaking on supercritical topography: The one-and two-ridge cases. J. Phys. Oceanogr., 43, 1380-1397, https://doi.org/10.1175/JPO-D-12-061.1.

Kunze, E., L. K. Rosenfeld, G. S. Carter, and M. C. Gregg, 2002: Internal waves in Monterey submarine canyon. J. Phys. Oceanogr., 32, 1890-1913, https://doi.org/10.1175/1520-0485(2002) 032<1890:IWIMSC $>2.0$. CO; 2 .

Kurapov, A. L., G. D. Egbert, J. S. Allen, R. N. Miller, S. Y. Erofeeva, and P. M. Kosro, 2003: The $M_{2}$ internal tide off Oregon: Inferences from data assimilation. J. Phys. Oceanogr., 33, 1733-1757, https://doi.org/10.1175/2397.1.

Legg, S., and K. M. Huijts, 2006: Preliminary simulations of internal waves and mixing generated by finite amplitude tidal flow over isolated topography. Deep-Sea Res. II, 53, 140-156, https://doi.org/10.1016/j.dsr2.2005.09.014.

Lerczak, J. A., C. D. Winant, and M. C. Hendershott, 2003: Observations of the semidiurnal internal tide on the southern California slope and shelf. J. Geophys. Res., 108, 3068, https:// doi.org/10.1029/2001JC001128.

Marshall, J., C. Hill, L. Perelman, and A. Adcroft, 1997: Hydrostatic, quasi-hydrostatic, and nonhydrostatic ocean modeling. J. Geophys. Res., 102, 5733-5752, https://doi.org/10.1029/96JC02776.

Nagai, T., and T. Hibiya, 2015: Internal tides and associated vertical mixing in the Indonesian Archipelago. J. Geophys. Res. Oceans, 120, 3373-3390, https://doi.org/10.1002/2014JC010592.

Nash, J. D., E. Kunze, J. M. Toole, and R. W. Schmitt, 2004: Internal tide reflection and turbulent mixing on the continental slope.
J. Phys. Oceanogr., 34, 1117-1134, https://doi.org/10.1175/15200485(2004)034<1117:ITRATM>2.0.CO;2.

- M. H. Alford, and E. Kunze, 2005: Estimating internal wave energy fluxes in the ocean. J. Atmos. Oceanic Technol., 22 1551-1570, https://doi.org/10.1175/JTECH1784.1.

— S. M. Kelly, E. L. Shroyer, J. N. Moum, and T. F. Duda, 2012: The unpredictable nature of internal tides on continental shelves. J. Phys. Oceanogr., 42, 1981-2000, https://doi.org/ 10.1175/JPO-D-12-028.1.

Oke, P. R., and P. Sakov, 2008: Representation error of oceanic observations for data assimilation. J. Atmos. Oceanic Technol., 25, 1004-1017, https://doi.org/10.1175/ 2007JTECHO558.1.

Ponte, A. L., and B. D. Cornuelle, 2013: Coastal numerical modelling of tides: Sensitivity to domain size and remotely generated internal tide. Ocean Modell., 62, 17-26, https://doi.org/ 10.1016/j.ocemod.2012.11.007.

Rayson, M. D., N. L. Jones, and G. N. Ivey, 2012: Temporal variability of the standing internal tide in the Browse Basin, Western Australia. J. Geophys. Res., 117, C06013, https:// doi.org/10.1029/2011JC007523.

Stewart, K. D., A. M. Hogg, S. M. Griffies, A. P. Heerdegen, M. L. Ward, P. Spence, and M. H. England, 2017: Vertical resolution of baroclinic modes in global ocean models. Ocean Modell., 113, 50-65, https://doi.org/10.1016/ j.ocemod.2017.03.012.

Van Gastel, P., G. N. Ivey, M. J. Meuleners, J. P. Antenucci, and O. Fringer, 2009: The variability of the large-amplitude internal wave field on the Australian North West Shelf. Cont. Shelf Res., 29, 1373-1383, https://doi.org/10.1016/ j.csr.2009.02.006.

Zhao, Z., and M. H. Alford, 2009: New altimetric estimates of mode- $1 M_{2}$ internal tides in the central North Pacific Ocean. J. Phys. Oceanogr., 39, 1669-1684, https://doi.org/10.1175/ 2009JPO3922.1.

Zilberman, N. V., J. M. Becker, M. A. Merrifield, and G. S. Carter, 2009: Model estimates of $M_{2}$ internal tide generation over Mid-Atlantic Ridge topography. J. Phys. Oceanogr., 39, 26352651, https://doi.org/10.1175/2008JPO4136.1.

—, M. A. Merrifield, G. S. Carter, D. S. Luther, M. D. Levine, and T. J. Boyd, 2011: Incoherent nature of $M_{2}$ internal tides at the Hawaiian Ridge. J. Phys. Oceanogr., 41, 2021-2036, https://doi.org/10.1175/JPO-D-10-05009.1. 